Invited critical review

\title{
The future of laboratory medicine - A 2014 perspective
}

\author{
Larry J. Kricka $^{\mathrm{a}, *}$, Tracey G. Polsky ${ }^{\mathrm{a}, \mathrm{b}}$, Jason Y. Park ${ }^{\mathrm{c}}$, Paolo Fortina ${ }^{\mathrm{d}, \mathrm{e}}$ \\ a Department of Pathology and Laboratory Medicine, University of Pennsylvania School of Medicine, 7.103 Founders Pavilion, 3400 Spruce Street, Philadelphia, PA 19104, USA \\ b Department of Pathology and Laboratory Medicine, Children's Hospital of Philadelphia, Philadelphia, PA 19104, USA \\ c Department of Pathology and the Eugene McDermott Center for Human Growth and Development, University of Texas Southwestern Medical Center, Children's Medical Center, \\ 1935 Medical District Drive, Dallas, TX 75235, USA \\ d Cancer Genomics Laboratory, Kimmel Cancer Center, Department of Cancer Biology, Sidney Kimmel Medical College, Thomas Jefferson University, Philadelphia, PA, USA \\ e Department of Molecular Medicine, Universita' La Sapienza, Rome, Italy
}

\section{A R T I C L E I N F O}

\section{Article history:}

Received 11 August 2014

Received in revised form 3 September 2014

Accepted 4 September 2014

Available online 16 September 2014

\section{Keywords:}

Predictions

Future

Laboratory medicine

Clinical chemistry

Molecular pathology

\begin{abstract}
A B S T R A C T
Predicting the future is a difficult task. Not surprisingly, there are many examples and assumptions that have proved to be wrong. This review surveys the many predictions, beginning in 1887 , about the future of laboratory medicine and its sub-specialties such as clinical chemistry and molecular pathology. It provides a commentary on the accuracy of the predictions and offers opinions on emerging technologies, economic factors and social developments that may play a role in shaping the future of laboratory medicine.
\end{abstract}

(c) 2014 Elsevier B.V. All rights reserved.

\section{Contents}

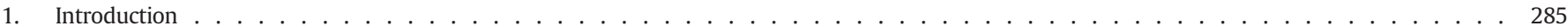

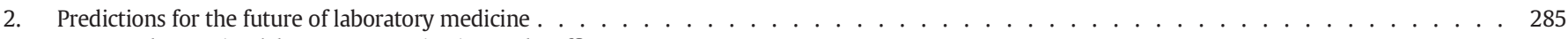

2.1. Laboratories, laboratory organization and staffing . . . . . . . . . . . . . . . . . . . . . . . . . . . . . 285

2.2. Automation and robotics . . . . . . . . . . . . . . . . . . . . . . . . . . . . 290

2.3. Computing and information technology . . . . . . . . . . . . . . . . . . . . . . . . . . . . . 291

2.4. Analytical techniques and technologies . . . . . . . . . . . . . . . . . . . . . . . . . . . . . . . 292

2.5. Point-of-care testing . . . . . . . . . . . . . . . . . . . . . . . . . . . . . . . 293

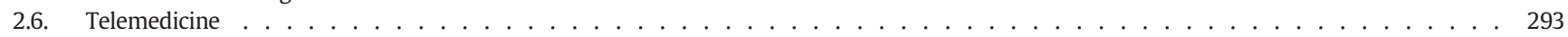

2.7. Microtechnology . . . . . . . . . . . . . . . . . . . . . . . . . . . . . . . . 295

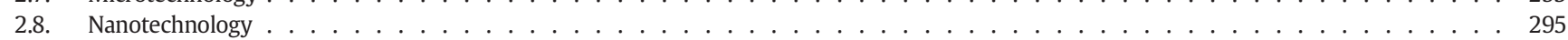

2.9. Genomics . . . . . . . . . . . . . . . . . . . . . . . . . . . . . . . . . . 295

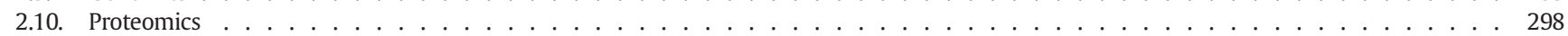

2.11. Evidence-based medicine . . . . . . . . . . . . . . . . . . . . . . . . . . . . 298

2.12. Microscopy and histopathology . . . . . . . . . . . . . . . . . . . . . . . . . . . . . . . . . 299

Abbreviations: ACO, Accountable Care Organizations; AEC, Atomic Energy Commission; ASCP, American Society for Clinical Pathology: ASIMO, Advanced Step in Innovative Mobility; BNP, brain natriuretic peptide; BRCA, breast cancer antigen; CAP, College of American Pathologists; CLIA, Clinical Laboratory Improvement Amendments; CMV, cytomegalovirus; DNA, deoxyribonucleic acid; eMERGE, Electronic Medical Records and Genomics; FACS, fluorescence-activated cell sorting; FDA, US Food and Drug Administration; GC, gas chromatography; GDP, gross domestic product; HER2, human epidermal growth factor receptor 2; HIV, human immunodeficiency virus; HIPAA, Health Insurance Portability and Accountability Act; HITECH, Health Information Technology for Economic and Clinical Health Act; HPLC, high performance liquid chromatography; HPV, human papillomavirus; IOM, Institute of Medicine; ISO, International Standards Organization; IT, information technology; IVDMIA, In Vitro Diagnostic Multivariate Index Assay; MALDI, matrix-assisted laser desorption ionization; MEMS, micro-electromechanical; mRNA, messenger RNA; MS, mass spectrometry; NCI, National Cancer Institute; NICE, National Institute for Health and Care Excellence; NIH, National Institutes of Health; NMR, nuclear magnetic resonance; PBMs, Pharmacy Benefit Managers; PCR, polymerase chain reaction; RFID, radio-frequency identification; RNA, ribonucleic acid; RT-PCR, reverse transcription PCR; SNP, single nucleotide polymorphism; TOF, time of flight; USB, Universal Serial Bus.

* Corresponding author.

E-mail address: kricka@mail.med.upenn.edu (L.J. Kricka). 
3. Predictions for laboratory medicine in regions and countries . . . . . . . . . . . . . . . . . . . . . . . . . . . . . . . . . . . . 299

4. The future of laboratory medicine in the context of the future of medicine and healthcare . . . . . . . . . . . . . . . . . . . . . . . . . 299

5. Conclusions . . . . . . . . . . . . . . . . . . . . . . . . . . . . . . . . . . . . . . 300

Acknowledgments . . . . . . . . . . . . . . . . . . . . . . . . . . . . . . . . . . . . . . 300

References... . . . . . . . . . . . . . . . . . . . . . . . . . . . . . . . . . . . . . 300

\section{Introduction}

Attempting to predict the future or being dogmatic about what may or what may not transpire in the future is a risky business, and history provides numerous examples of predictions and assumptions that have proved to be wrong.

Spectacularly inaccurate predictions abound in the field of consumerism and computing. In 1966, Time magazine stated, "Remote shopping, while entirely feasible, will flop" [1]. In 2012, the US online retail sector had total revenues of more than $\$ 200$ billion, with a compound annual growth rate of $11.0 \%$ between 2008 and 2012 [2]. The launch of the iPod drew the following comment from the founder of a major consumer electronics company in 2005: "Next Christmas the iPod will be dead, finished, gone, kaput” [3]. By January 2007, the iPod US market share of digital music player sales had reached 72.7\% [4]. In 2007, the CEO of Microsoft advanced the opinion that "There's no chance that the iPhone is going to get any significant market share. No chance" [5]. By the end of fiscal year 2010, a total of 73.5 million iPhones had been sold [6].

The early days of computing also produced some famously erroneous predictions. In 1943, the chairman of IBM said, "I think there is a world market for maybe five computers" [7]. Another highly respected member of the early computer industry, the president, chairman and founder of Digital Equipment Corp., explained in 1977, "There is no reason anyone would want a computer in their home" [3]. Despite these predictions, a US Department of Commerce survey from 2011 showed that $75.6 \%$ of households in the United States reported having a computer [8]. In fact, computer makers shipped more than 85 million computers in the second quarter of 2012 [9], and the worldwide PC, tablet and mobile phone combined shipments were approximately 2.2 billion that same year [10].

The prognosticator usually bases predictions on contemporaneous information and perceived trends. Picking the relevant trends and identifying transformative technologies is generally more of an art than a science. For example, an emerging and ultimately successful technology can be at any of a number of stages of development, and these can influence the perception of its influence and contribution to future developments. These stages, characterized by the Gartner Hype Cycle, include "a peak of inflated expectations", "a trough of disillusionment" and end with "a plateau of productivity" [11]. Clearly, greater weight likely will be attributed to the future influence of a technology when it is at the peak of inflated expectations, compared to when it has descended into a trough of disillusionment.

Many authors have offered predictions regarding the future of laboratory medicine and its subspecialties. This article reviews the literature that prognosticates on the future of laboratory medicine and provides a 2014 perspective of the future of laboratory medicine.

\section{Predictions for the future of laboratory medicine}

There is no shortage of predictions about the future of laboratory medicine. These fall into two categories; the first category includes general predictions for the future while the second represents predictions for specific dates in the future (Table 2) [12-48].

An interesting starting point is the Inaugural lecture, titled "A view from a bridge," given in 1969 by Tom Whitehead, the first Chair of Clinical Chemistry at the University of Birmingham [16]. He identifies five eras of clinical chemistry: The complicated era from 1920 to 1940 when testing was manual and laborious, the simplified era from 1940 to early 1950s when test procedures were simplified, the crisis era in the late 1950s when the test workload doubled every 4-5 years, the sophisticated era in the late 1960s based on new automation and computing technology, and the profile era in the 1970s when tests were bundled together as profiles in order to improve laboratory efficiency and to detect biochemical abnormalities that would not have been detected by clinical examination (Table 3 ). He also points to the continuing importance of computers and automation, in addition to the emergence of preventative medicine and pharmacogenetics.

There is merit in each of these predictions. For example, profiling has re-emerged in clinical testing in the form of protein, tissue and nucleic acid arrays (e.g., cytokine profiles, array comparative genomic hybridization analysis) [49-52]. Computers and automation have played an increasingly important role in improving the efficiency and effectiveness of testing. More recently, pharmacogenetics, popularized by the slogan "right patient, right drug, right time" [53], has moved into mainstream testing (e.g., CYP2C9 for warfarin dosing) [54].

Since 1969, there have been many predictions and views of the future development of laboratory medicine and its sub-specialties. A summary of these predictions is provided in Table 1 [12-48]. A number of common themes and buzz-words can be identified in the prognostications such as nanotechnology, biosensors, microchips, genomics, and proteomics. These topics, together with the more specific predictions, are discussed in greater detail below.

\subsection{Laboratories, laboratory organization and staffing}

Early publications predicted "as many as two workers in the laboratory" at large medical centers and specified that the roles of laboratorian and pharmacist would be combined [15]. By 1989, the emphasis had shifted to concerns about the impending shortages of pathologists [24], a concern that has continued into the 2000s [33].

In more recent times, futurists have predicted a world dominated by large supra-regional tertiary centers or laboratory networks formed by laboratory consolidation $[35,46]$. Contraction in the number of laboratories would be driven by out-sourcing of laboratory services, competition between laboratories for hospital work, and the commoditization of laboratory tests $[28,34,35]$. A positive trend would be possible growth due to refocusing of clinical laboratory services due to changing demographics (e.g., emphasis on diseases of the elderly and reassessment of location of services) [28]. Within laboratories, integrated services staffed by clinical laboratory scientists may lead to further contraction (e.g., hematology, transfusion medicine, biochemistry and immunology merged into a unified "blood sciences") [46]. Staff would be responsible for demand management, greater components of user education and the provision of additional consultative services related to laboratory testing. In the context of increased point-of-care testing, the future role of laboratorians would be reduced to maintaining equipment and performing quality control [19]. Other predictions focus on the challenges of global harmonization of in vitro diagnostic tests, reducing laboratory errors and eliminating unnecessary testing [33].

Early predictions for the scale and scope of clinical laboratories (e.g., a total of two workers in the laboratory) were off the mark (see Fig. 1 that contrasts a clinical laboratory in 1904 and 2014). However, predictions about a combined laboratorian pharmacist may have been accurate 100 years later with the advent of personalized medicine [55]. More importantly, predictions on laboratory consolidation have 
Table 1

Predictions for laboratory medicine made on a specific date or about specific dates and periods in the future.

Predictions made on a specific date about the future

Predictions made in 1887 [12]

- Improved methods for examining living tissues, ex vivo.

- Microscopy will be improved to visualize structures that cannot be seen.

Predictions made in 1889 [13]

- Use of the microscope and chemical methods will aid in discovering the mechanisms of diseases.

Predictions made in 1906 [14]

- "The future is, no doubt, to the pathologist, and if diagnosis, prognosis, and treatment of disease are to depend mainly upon blood examination and bacteriology, the general practitioner may have to carry out these examination himself or sink to the level of a mere collector and transmitter of blood and sputum, while the consulting pathologist pulls the strings of the treatment."

Predictions made in 1920 [15]

- Laboratory professionals who do not directly interact with patients would be paid entirely by a fixed salary.

- Clinicians with direct contact would be paid fee for service.

- Primary service of laboratories is to the general clinical practitioners "to enable him personally to make any examinations he desires to undertake".

- Skill level of the director varies with medical center size, geographic location and specialization.

- Larger medical centers may combine the roles of laboratorian and pharmacist.

- At the largest medical centers, as many as two workers in the laboratory may be necessary.

- Communication between laboratory centers will be by telephone or motor vehicle.

- The laboratory specialties will include morbid anatomy, bacteriology and pathological chemistry.

- The health services laboratory will be separate, but in close contact with the 'professorial department'.

- "No rigid barrier should be erected between the academic pathologist and those engaged in the health services".

Predictions made in 1969 [16]

- Emergence of toxicogenetics and pharmacogenetics in the context of preventative medicine.

- Greater use of automation and computers.

Predictions made in 1970 [17]

- Doctors' offices, hospitals and clinical laboratories will share information "on-line" through a remotely located computer.

- 'Automated ordering' - 1. doctor writes a lab order; 2 . order is given to a receptionist; 3 . receptionist calls the patient and the laboratory to schedule a phlebotomy appointment; 4. appointment slip is typed on a typewriter in duplicate (one copy for the patient and one for the office record); 5 . the typewriter updates information to the remotely located computer; and 6 . the remotely located computer generates a daily work list via automated typewriter at the laboratory.

- Patient records are centrally located in the computer.

- Entire medical record can be sent to another city via punched paper tape or automated typewritten hardcopy.

- Physicians may review documents via video terminal (standard telephone line service is cited to soon be as fast as one page per 2 min at a cost of $\$ 8.50$ per month).

Predictions made in 1978 [18]

- Analytical systems capable of testing for hundreds and thousands of different substances.

- Development of human molecular anatomy.

- On the verge of a cataclysmic revolution in terms of the complexity of data generated.

Predictions made in 1980 [19]

- Point of care testing and the proliferation of diagnostic kits.

- Empowerment of patients to perform tests previously only done by trained clinical chemists.

- Laboratory methods will be developed that sleep-deprived surgeons can perform in an acceptable manner.

- Future role for laboratorians in maintain equipment and performing quality control.

Predictions made in 1985 [20]

- Testing will become decentralized into doctor's offices and patient rooms.

Predictions made in 1985 [21]

- Clinical laboratory testing will become decentralized, but the decentralization will not improve the interpretation of test results.

- Chemical pathologists will become a specialist like radiologists using chemical analysis instead of X-ray imaging. They will develop methods to solve patient problems and become more of specialist and less of a manager.

- Hospital based laboratory testing will disappear and be replaced by centers of testing outside of the hospital.

Predictions made in 1986 [22]

- The success of laboratory medicine depends on not only analytical performance but also ordering practices and reporting.

- The future of laboratory medicine will be guided by cost containment.

- New technologies such as DNA hybridization cross many traditional laboratory specialties and may require a new management structure for effective utilization.

Predictions made in 1987 [23]

- Advances in technology allow for consolidation of multiple laboratory specialties: chemistry, toxicology, hematology, microbiology and immunology.

- Consolidation and centralization of laboratory specialties will have financial benefits.

- Miniaturized and automated technology enables laboratory technology to be deployed closer to the patient (e.g., emergency rooms, physician offices, patient homes).

- Automated laboratory tests will decrease the need for professionals with analytical skills, but will increase the need for managers that operate and integrate new laboratory technologies in a cost-effective manner.

Predictions made in 1989 [24]

- Shortage of pathologists in community hospitals in the United States predicted to reach between 400 and 600 FTE by 1992.

- Predicts increasing retirement, decreasing trainees, expansion of technology and an aging population requiring more laboratory services.

Predictions made in 1990 [25]

- Robotics, biosensors and micromachine technology, neonatal genetic screening.

Predictions made in 1990 [26]

- Improved chromatographic and immunological techniques, novel types of mass spectrometry, biosensors, in vivo nuclear magnetic resonance spectroscopic probes, new intracellular probes, new types of toxicological assays, advanced computer and information technology.

Predictions made in 1994 [27]

- Universal automated immunoassay analyzers, standardization of immunological measurements, number and specificities of immunological analytes to increase, antigens produced by recombinant DNA techniques, more functional analyses, development of less-complex tests.

Predictions made in 1995 [28]

- Clinical chemist to develop cross-disciplinary expertise and become a clinical laboratory scientist.

- Consolidation and integration of clinical laboratories.

- Out-sourcing of laboratory services.

- Competition between laboratories for hospital work

- Increased automation, transport modules to deliver specimens to analyzers. Personalized reference intervals.

- Artificial intelligence for result interpretation. 
Table 1 (continued)

Predictions made on a specific date about the future

- Widespread use of DNA probes.

- Intracellular metabolic studies based on fine needle biopsies and FACS.

- In vivo blood gas, oximetry and bilirubin measurements.

- Refocusing of clinical laboratory services due to changing demographics (emphasis on diseases of the elderly and reassessment of location of services) Expanded role for noninvasive diagnosis (e.g., nuclear magnetic resonance of whole body or organs, probes for the mouth and other body cavities).

Predictions made in 1996 [29]

- Distributed systems based on client/server computer architecture.

Predictions made in 2000 [30]

- Expanded use of database software for genomic and proteomic screening to increase efficiency of clinical assay development.

Predictions made in 2001 [31]

- Counter-top gene sequencers for predicting effectiveness of drugs.

- Endorsement and reimbursement of laboratory testing as a "predict-and-manage" strategy.

- Increased demand for clinical laboratory services as population ages.

- Consumerism encourages more medical testing.

- Digital solutions (electronically distributed lab test results).

- Increased automation and computer-based analysis.

- Chronically ill and homebound maintain a continuous record of lab data preserved on personal electronic medical record.

- Online access to laboratory test results.

Predictions made in 2004 [32]

- Entering era of molecular diagnostics and pathology; pharmacogenetic and pharmacogenomic testing.

Predictions made in 2006 [33]

- Staff shortages.

- Increase in point-of-care testing, home testing and noninvasive testing.

- Increased use of tandem mass spectrometry.

- Increased use of molecular diagnostics (chips, SNPs, single cell analysis).

- Use of robotics.

- Telecommuting.

- Challenges will include global harmonization of IVDs, nanotechnology, reducing laboratory errors and unnecessary testing, population demographics, international competition in healthcare.

Predictions made in 2007 [34]

- New business model for the operational organization of clinical laboratories based on consolidation, integration, and virtual laboratories.

- Commoditization of tests.

- Provision of additional knowledge services relating to testing.

Predictions made in 2010 [35]

- Laboratory networks.

- Commoditization of laboratory tests.

- Greater components of user education and demand management.

Predictions made about specific dates or periods in the future

Predictions made in 1977 about 1982-1987 [36]

- Automation, non-isotopic immunoassays, HPLC-based analyses, GC-MS-based assays (fingerprinting microorganisms), multicomponent analysis (metabolic profiles), cell sorting.

Predictions made in 1980 about 1981-2001 [37]

- Computer assisted interpretation of tests.

- More computer capacity for monitoring of quality and plausibility

- Increased concern with data interpretation and organizational problems.

Predictions made in 1985 about 1986 to 1995 [20]

- Growth of drug monitoring and clinical immunology.

- Laboratory testing will move closer to patients with direct testing of patients in operating rooms, intensive care units and patient rooms.

Predictions made in 1985 about 1990 to 1995 [21]

- Clinical laboratory testing will become decentralized.

Predictions made in 1988 about 1993 to 2008 [38]

- Technology of mapping and sequencing the human genome will take another 5-10 years and sequence of human genome will take from 10 to $20+$ years.

Predictions made in 1993 about 2000s [39]

- Important role of miniaturization, molecular biology, whole blood assays, and more sensitive instrumentation.

Predictions made in 1995 about 2000-2005 [40]

- Continued evolution of front-end specimen management systems.

- Non-invasive instrumentation.

- Advances in cellular diagnostics, image analysis and immunocytometry, DNA probes, amplification technology and quantitative techniques on easy-to-use instruments.

- Viral load monitoring and new tests for management of cancer and central nervous system disorders.

- Microchips and micromachines transform instrumentation.

- Multianalyte detection (DNA microchips).

- Diagnostic instruments to become portable, simple and flexible.

- In vivo imaging with antibody fragments.

- Innovation driven by the electronic superhighway (e.g., voice-activated recognition systems).

- Addition of hundreds of possible diagnostic tests based on the human genome project.

- Smaller, lower-cost point of care instruments with built-in quality control systems and very broad menus.

- Increase in role of near-patient testing (5-10\% of all testing by 2000).

Predictions made in 1996 about 2001-2006 [41]

- Computers report laboratory data with graphics.

- Image storage and transmission of reports.

Predictions made in 1996 about 2006-2016 [41]

- Focus on preventative medicine.

- Integration of molecular medicine, information and computer technology.

- Predictive tests (risk factors). 
Table 1 (continued)

Predictions made about specific dates or periods in the future

- Miniaturization of analytical devices and DNA chip technology.

- Strong influence from molecular biology, genomics, combinatorial chemistry, robotics, micro electronics and informatics, pharmacogenomic profiling, nanotechnology.

- Large-scale hyperlinked data banks for patient care and new informatic tools and systems (algorithms for data mining, databanks for gene-disease risk correlations,

encryption methods to ensure privacy and confidentiality).

- Mass spectrometry for protein expression profiles.

Predictions made in 1997 about 2007-2017 [42]

- Technologies with greatest impact - molecular diagnostics, near patient testing (via biosensors), image analysis, robotics, information management (telepathology, voice recognition, hand-held devices for test ordering/result retrieval).

Predictions made in 1999 about the third millennium [43]

- Importance of diagnostic gene chips and nanotechnology.

Predictions made in 2000 about 2001-2009 [44]

- Nanotechnology enables micrototal analytical systems, single cell analysis

- Greater integration of point of care testing into patient management strategies and pathways of care.

- Pharmacogenomics to allow individualized dosing with drugs.

- Proteomic studies provide basis for future diagnostic tests.

- Evidence based medicine combined with experience-based medicine to provide effective route for diagnosis and treatment.

Predictions made in 2002 for 2003-2012 [45]

- Transformation of healthcare science and the regulation and training of staff.

Predictions made in 2006 about 2026 [46]

- Laboratories organized as large supra-regional tertiary centers and local centers (large private laboratory providers dominate).

- Large pharmaceutical companies and private laboratory services to provide pharmacogenomic and metabologenomic services in the home.

- "All-contained drop-down" modules will feature prominently in new laboratories to offer flexibility and expandability.

- High dependence on robotics, automated specimen handling, automated specimen tracking and humanoid technology.

- European consortium to bring together public and private laboratories to develop vital sign technology (telemedicine).

- Telemedicine, remote controlled microscopy, artificial intelligence microscopy, internet communication, remotely accessible telepathology workstation platforms.

- Artificial intelligence automated cytoscreening technology.

- Nuclear magnetic resonance microscopy (cellular metabolo-imaging).

- Integration of hematology, transfusion medicine, biochemistry and immunology into a unified "blood sciences".

- Specimen identification chips (Spec-Chip) incorporate sample identification and patient record within the sample cuvette.

- Semi-permanent implanted personal profile chip for detection of disease signatures in peripheral blood.

- Diagnostic nano-robots for monitoring of disease.

- Population microgenomics.

- Lab-on-a-chip devices for microbiology and infectious disease testing

- Hand-held devices for top eight infectious pathogens will be available for monitoring.

- High-density SNP diagnostic assays commonplace (e.g., for profiling tumors).

- High-density antibody and protein chip arrays for immune disease testing and assessing immune response.

- Individual patient genome signature profiling commonplace.

- Twenty-four color chromosome karyotyping/spectral analysis of tumors routinely offered in hematological malignancies and solid tumors.

- Electrochemical detection of infectious agents, gene mutations, specific gene transcripts and proteins using devices in a primary healthcare setting.

- Microelectromechanical (MEMS) devices used to inoculate individual red cells in vivo.

- Nanoparticles used to seek out specific cells.

- Nano-encapsulation and nano-robot technology for drug delivery.

- Smart medical implants using biosensors and fuel cells (active real-time autonomous monitoring).

- Implantable radiofrequency identification (RFID) microchips.

- Humanoid technology in use in laboratories.

Predictions made in 2012 about 2013-2017 [47]

- Slow introduction of pharmacogenomic testing into primary care

- Focus of genomics research and application will shift into the primary care setting

- Increase in consumer demand for pharmacogenomic testing

- Primary care theranostics to become a significant portion of healthcare

Predictions made in 2012 about 2020 [48]

- Smartphone (or a tablet device) as the hub of medicine

- Smartphone-enabled portable laboratory (lab-on-a-chip devices)

- Individuals who have had their genome sequenced increasingly common

been on point, as evidenced by the rise of national reference laboratories such as ARUP, Quest Diagnostics and LabCorp. In addition, over the past fifty years, some have predicted that the development of miniaturized point-of-care testing devices would de-centralize laboratory testing. If we consider the large direct-to-consumer market for patient testing (blood glucose, pregnancy testing, urine analysis) and doctors' office testing, perhaps we see two simultaneous trends: consolidation of traditional laboratory testing and an expanding new market for near-patient testing.

The identification of cost containment as a major factor in the future of laboratory medicine was correct [22], as well as an emphasis on the cost-effective operation of laboratories [23]. There is a continuing trend to unify independent hospitals into Health Systems and to consolidate specialty laboratories (e.g., immunology, microbiology and chemistry) into a Core Laboratory model. In many parts of the world, the laboratory services for geographic regions and whole nations are coordinated to serve vast populations. One prominent example is the establishment of the Calgary Laboratory Services (CLS) in Alberta, Canada [56]. In 1994, the health authority of Alberta began consolidating healthcare services for the city of Calgary and its surrounding regions. The consolidation included the closure of hospitals and centralization of laboratory services. By the end of 1995, there was a sole provider for all laboratory services in the Calgary region. A central principle guided the organization of laboratory services: all tests with a turnaround time of $>2 \mathrm{~h}$ were centralized into a single high volume laboratory. Only STAT or urgent testing capabilities remained in the hospital-based laboratories. Today, two decades later, this single entity continues to coordinate laboratory services for a metropolitan region with a population of over a million people.

The prediction for "blood science" laboratories also has been correct as evidenced by the Blood Science Laboratory at the University Hospital Birmingham NHS Foundation Trust in the UK. This brand-new automated laboratory combines chemistry, immunoassay, serology, transfusion, blood counts/films, and coagulation testing [57]. 
Table 2

Predictions made about medicine and healthcare.

Predictions made in 1900 about 2001 [183]

- Few drugs will be swallowed - drugs will be applied directly to organs through the skin and flesh via an electric current applied without pain to the outside skin of the body.

- Microscopes will lay base the vital organs, through the living flesh, of men and animals. The living body will to all medical purposes be transparent using rays of invisible light.

Predictions made in 1955 about 1999 [184]

- 150-year life span, infectious disease eradicated, cancer treated using a vaccine, surgical techniques to restore sight, deaf-mute to speak electronically.

Predictions made in 2012 about 2020 [185]

- Organ printing (aka bio-printing, bio-manufacturing or computer-aided tissue engineering), synthetic blood, personalized medicine to provide the right drug to the right patient at the right time, stem cell treatments

Predictions made in 2012 about 2022 [186]

- Nanoparticles will make chemotherapy far more effective by delivering tiny doses of drug right to cancerous cells.

- Your genome will be sequenced before you are born

- Drugs will be tested on "organ chips" that mimic the human body.

- Genetic testing will be used to halt epidemics. Vaccines will wipe out drug addiction.

Predictions made in 2012 about 2030 [187]

- Life expectancy of 150 years

Predictions made in 2012 about 2032-2062 [186]

- Checkups will be conducted by cell phone.

Predictions made in 2012 about 2063-2122 [186]

- Your body will be truly connected and your vital signs checked around the clock via tiny sensors

- Stomach chips will monitor your diet to help you lose weight

- Spinal cord implants will reverse paralysis

- Brain chips will let you absorb data while you sleep

- Brain interfaces will help you fully inhabit virtual worlds

Predictions made in 2013 about 2014 [188]

- Rise of telemedicine - "the virtual doctor will see you now"

- Shop for your health care - greater price transparency and consumerism

- Expanded mental health care coverage

- Side-effects of the physician shortage - boomers may lose their doctors

- More at-work clinics - see a doctor during your work break

Predictions made in 2013 about 2045 [189]

- Brain implants unlock the power of the cloud

- Functional brain map leads to post-brain-map era

- Immortality is real - brain kept alive in a robotic surrogate or uploaded to silicon

The concern for laboratory staffing shortages is likely to continue. A 2012 ASCP survey in the US showed vacancy rates of $7 \%$ in core labs [58, 59]. Findings such as these may hasten strategies to reduce staffing needs, namely consolidation and automation. However, some types of consolidation, such as combining Radiology and Pathology, seem a remote prospect.

Declining reimbursement for laboratory tests will force laboratories to take further measures to reduce expenses, which may include a major role for test triage by laboratory professionals. But, over ordering of tests and inappropriate test requests will be difficult to control and enforce in the absence of penalties for offenders. Laboratory utilization models that have emerged in the past decade include laboratory formularies (e.g., University of Michigan, Brigham \& Women's Hospital and University of Rochester Medical Center) [60,61] and restricted access or uniform denial of access to tests deemed to have limited value (e.g., Calgary Laboratory Services) [62]. An important component of the success of these strategies is the management and enforcement by stakeholders outside of the laboratory. In the case of laboratory formularies, the chief medical officer and chief operating officer of the health system manage some of the recently implemented models. With the rise of international access to medical care services for expensive elective procedures, such as cardiac and orthopedic surgery, some experts have proposed the possibility of outsourcing clinical laboratory services to countries with equally sophisticated laboratory services, but significantly lower costs (e.g., labor and infrastructure) [63]. Indeed, there are continued efforts for international harmonization of laboratory testing quality programs and regulations through ISO (The International Standards Organization), CAP (College of American Pathologists) accreditation and CLIA (Clinical Laboratory Improvement Amendments) certification.

In addition to outsourcing and globalization of laboratory testing, there has been an increased migration of testing to the point-of-care. This transition may decrease reliance on hospital laboratories and reduce test volumes in hospital or regional laboratories. Empowering consumers through a wider range of home tests may further decrease test volumes in laboratories. Although it is possible that empowering consumers via deregulation of direct-to-consumer testing may increase overall test volumes, predicting the consumer response to a large menu of newly accessible diagnostic tests remains difficult at this time.

The internet has made information about disease and its diagnosis easily available. This widespread access to health-related information has spawned a new class of patients seeking to influence decisions on their healthcare (sometimes called "junior MDs"). New resources, such as Lab Tests Online, provide patients with extensive information about laboratory tests [64]. Similar to how physicians and laboratory professionals can access internet search engines, such as Google, to learn about the ordering and interpretation of the latest esoteric tests, patients also can readily investigate the tests they desire and the various interpretations. In the case of complex testing (e.g., genomics) that requires massive and constantly updated databases, companies have demonstrated consumer/patient interest in direct access to testing and its interpretation.

By better informing the patient, the internet may actually drive down the cost of laboratory testing. Multiple clinical laboratory test providers offer direct-to-consumer testing for a wide menu of tests. Not only will these direct-to-consumer tests increase patient options, but some providers also specify test prices. In the United States, patients are becoming more familiar with healthcare costs; laboratory testing will not be an exception. Therefore, it is anticipated that this increased level of patient education likely will lead to a class of better-informed and more-demanding patients in the future.

Table 3

Eras in clinical chemistry and genetic testing.

\begin{tabular}{|c|c|c|}
\hline Era & Clinical chemistry testing & Clinical genetic testing \\
\hline Complicated era - manual and tedious & $\begin{array}{l}\text { 1920-1940; clinical use of measuring hematologic } \\
\text { parameters and blood chemistries }\end{array}$ & 1977-1986; Sanger sequencing using radioactive reagents \\
\hline Simplified era - simplified test procedures & 1940s; laboratory instrumentation introduced & $\begin{array}{l}\text { 1987-2000; automated Sanger sequencing of single genes or point } \\
\text { mutations (fluorescent reagents) }\end{array}$ \\
\hline Crisis era - test workload doubling every $4-5$ years & 1950s; clinical laboratory testing becomes routine & $\begin{array}{l}\text { 2001-2009; post-human genome project, many genes do not have } \\
\text { a clinical test available }\end{array}$ \\
\hline $\begin{array}{l}\text { Sophisticated era - testing based on new } \\
\text { automation and computer technology }\end{array}$ & 1960s; automated chemistry analyzers & 2010-present; next-generation sequencing applied to panels of genes \\
\hline $\begin{array}{l}\text { Profile era - tests bundled together as profiles to } \\
\text { improve efficiency and detect abnormalities not } \\
\text { detected by clinical exam }\end{array}$ & 1970s-1984; multi-analyte analyzers & $\begin{array}{l}\text { 2012-present; next-generation sequencing applied to exome and } \\
\text { whole genome }\end{array}$ \\
\hline $\begin{array}{l}\text { Commoditization era - testing is routine and is } \\
\text { perceived as a commodity selected by quality and cost }\end{array}$ & 1985-present & To be determined \\
\hline
\end{tabular}


A

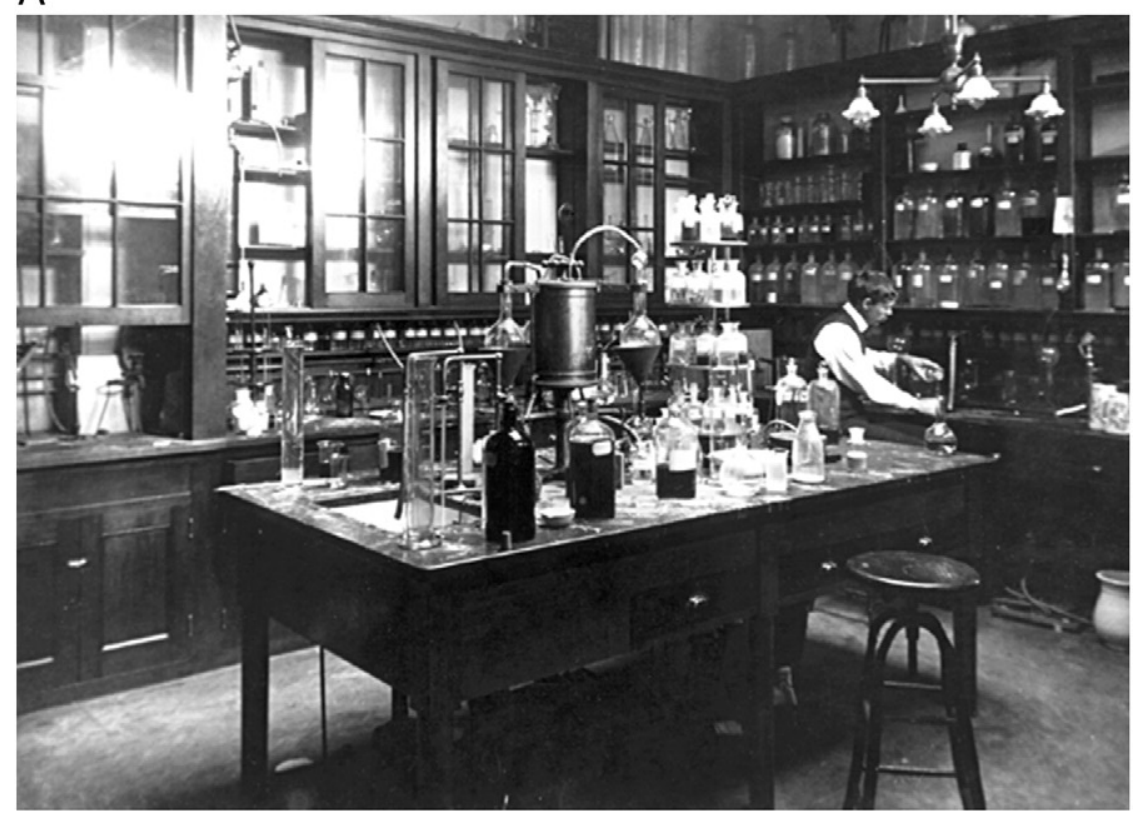

B

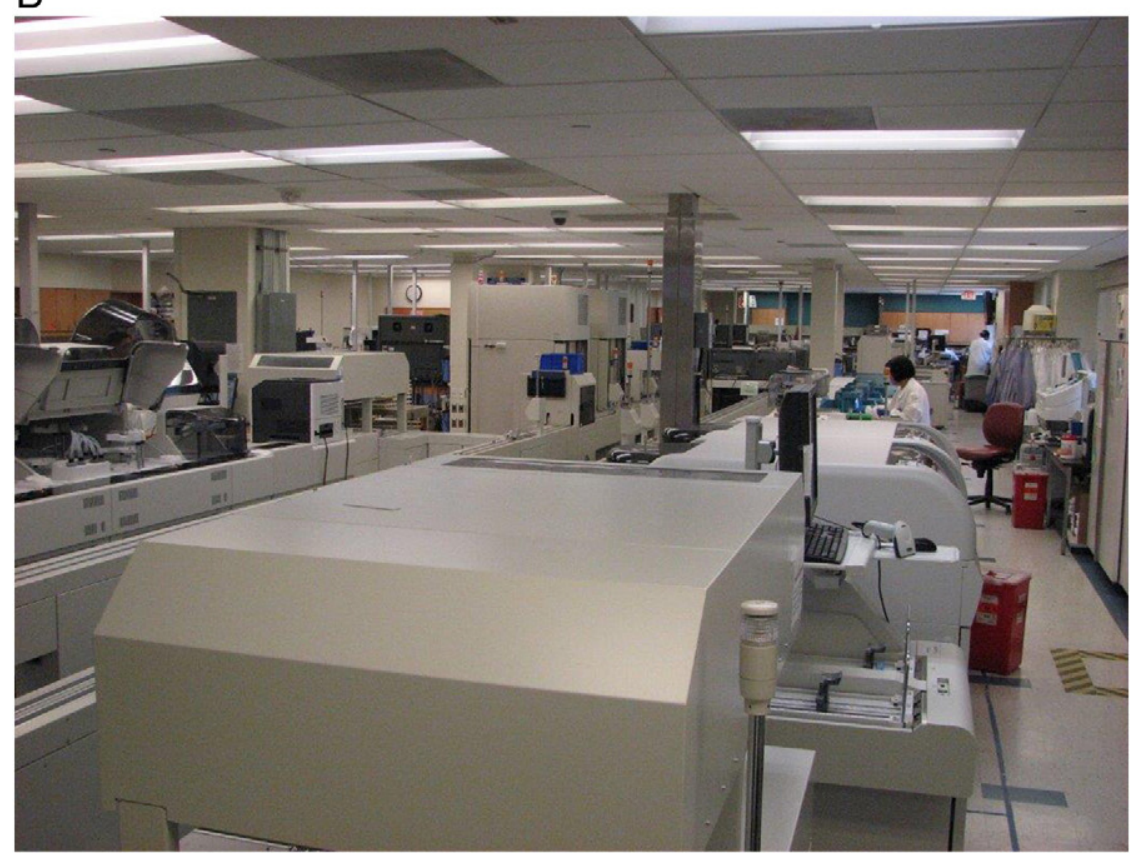

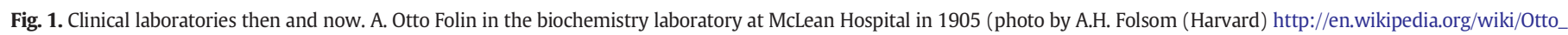

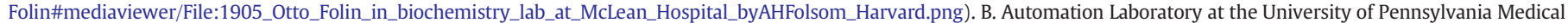
Center, Philadelphia, PA, USA in 2014.

Another consideration is that disruptive technologies may lead to dramatic changes. One company that currently is being predicted to change the delivery of laboratory services is Theranos [65]. The Theranos technology has been a closely guarded secret, which at the time of this publication is unknown. Reportedly, the technology allows up to 70 different tests, performed on a 25 to $50 \mu \mathrm{L}$ blood sample obtained from a finger stick, to be available within hours. The implementation of the technology will be through high-complexity CLIA-certified laboratories and Theranos plans to seek FDA clearance for it tests. It has teamed-up with a national pharmacy chain (Walgreens) to create blood collection centers ("Wellness Centers") in 21 of the 8200 Walgreens stores across the United States. Another feature of the Theranos business model is that it purposes to charge less than $50 \%$ of the standard Medicare and Medicaid reimbursement rates. This decreased charge is predicted to save Medicare $\$ 98$ billion and Medicaid $\$ 104$ billion over the next ten years [66]. Clearly, success of the Theranos technology and test delivery model would be disruptive for both hospital- and reference laboratory-based testing.

\subsection{Automation and robotics}

The evolution of automation and robotic methods in laboratories has been a popular prediction that includes front-end specimen management systems and automated specimen tracking $[40,46]$. More futuristic predictions describe transport modules to deliver specimens to analyzers and the use of humanoid technology $[28,46]$. "All-contained 
drop-down" modules (a fully operational analyzer in the form of a module) feature prominently in new laboratories to offer flexibility and expandability (46).

The various predictions about the growth of automation mostly have been correct. Many fully automated track and front-end specimen processing systems have been installed in clinical laboratories $(>2700$ installed in the US as of 2013) [67]. However, the notion that humans could be replaced with humanoid robots in the laboratory of the future has not become a reality. The current capabilities of humanoid robots are limited, but they certainly have the potential to do the types of tasks currently performed by humans (e.g., ASIMO from Honda and MOTOMAN from Yaskawa Electric) [68,69] (Fig. 2).

Although predictions for the use of automation may have been correct for clinical chemistry and hematology, automation and robotics have been slow to move into other areas of the laboratory such as microbiology, molecular pathology, and anatomic pathology. Also, unanticipated automation has occurred in the development of software. Middleware now allows for communication between analyzers, information systems and electronic medical records. The transfer of specimens from phlebotomy, to the laboratory, and then to analysis and result can be monitored in real-time. This has led to improved capabilities in quality management and efficiency.

It is expected that the demand for automation and/or robotics will increase, not only for cost efficiency, but also for maintenance of consistent, skilled specimen handling. The aging workforce has negatively impacted the availability of skilled laboratory workers, and there are many workforce predictions that highlight the future shortage [70]. In addition to becoming cheaper and easier to implement, robotics may be essential for laboratories of all sizes as the workforce shrinks. Humanoid robots are continuing to improve in their scope of capabilities (e.g., vision, tactile sensing, whole-body motion, manipulation). Therefore, it is not unreasonable to foresee a disruptive role for such machines in the laboratory of the future [71].

An obvious area for improvement is the simplification of the analyzerhuman user interface. Operation of analyzers remains relatively complex, and thus necessitates operators with a specific level of education and training. Simplification of the operator interface would provide both improvements in quality and the opportunity to employ less well-educated, and hence less costly, staff.

Overall, technology will continue to fuel the adoption of automated work systems in the clinical laboratory. Within the past twenty years, there has been surprising adoption of automation into cytology (Focalpoint) [72], microbiology laboratories (BD Kiestra - automated microplating, culturing and identification) and anatomic pathology (Ventana Symphony - automated H\&E slide-staining platform) [73].

\subsection{Computing and information technology}

In 1978, we were thought to be on the verge of a cataclysmic revolution in terms of the complexity of laboratory test data generated [18]. Several authors have pointed to the future development of large-scale hyperlinked data banks for patient care (e.g., databanks for genedisease risk correlations), distributed systems based on client/server computer architecture, and generally, innovation driven by the electronic superhighway [29,40,41]. Others have anticipated the use of artificial intelligence for result interpretation (e.g., automated cytoscreening), encryption methods to ensure privacy and confidentiality, voice recognition, and hand-held devices for test ordering/result retrieval $[41,42,46]$. A component of test ordering potentially may include implantable radio-frequency identification (RFID) microchips to facilitate facile and unambiguous patient identification [46].

Some predictions have pointed to improvements in data interpretation and presentation such as personalized reference intervals, expert systems [74] and the reporting of laboratory data with graphics.

Computing and information technology have come to underpin many aspects of laboratory medicine, and there is now a wide utilization of computers (data transmission, interpretation, manipulation, graphical reporting) and sophisticated information technology (IT) technology (remote servers, cloud computing). Concern about the security of health information has led the US federal government to enhance existing legislation of health information security (HIPAA - Health Insurance Portability and Accountability Act) in order to improve healthcare data security and specify protections of genetic data under HITECH (Health Information Technology for Economic and Clinical Health Act) [75]. One consequence of the maturation of IT technology has been that laboratory data is now directly available to consumers; this accessibility has been mandated by U.S. law [75].

The last ten years has seen the emergence of healthcare informatics and the application of computational algorithms to large data repositories. This has paralleled the tremendous growth in big data - the use of data warehouses, data management and analytics across many industries, not just healthcare [76]. The NIH established the eMERGE
A

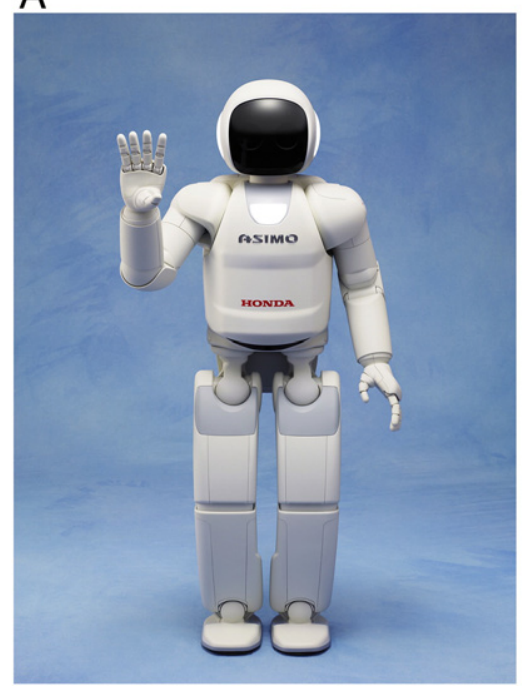

B

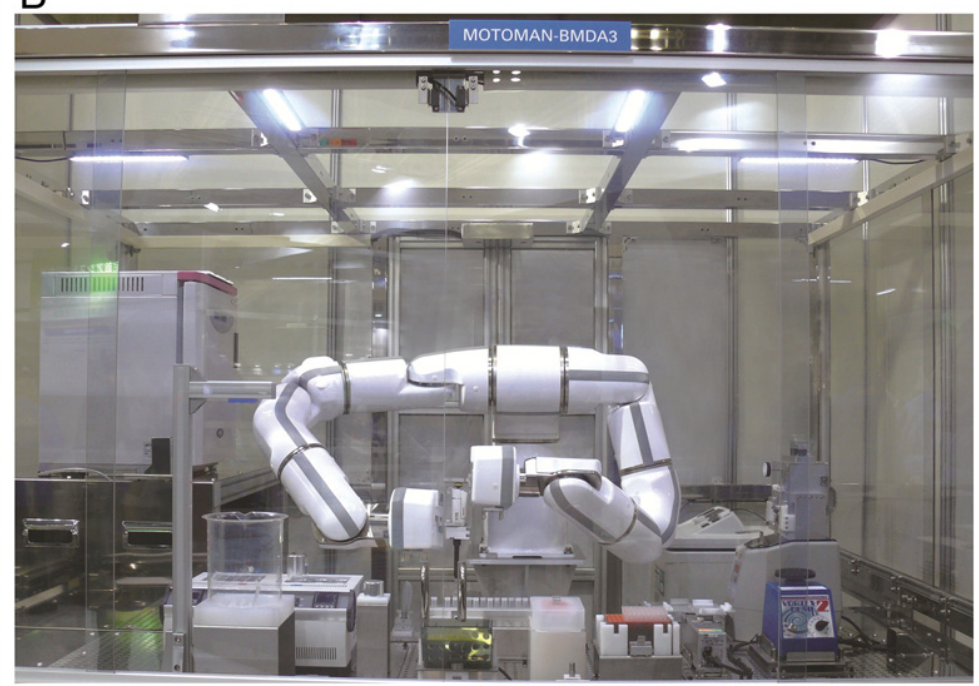

Fig. 2. A. Humanoid robot ASIMO (Honda) (reproduced with permission from Honda North America). B. Two-armed humanoid robot MOTOMAN (Yaskawa Electric Corporation) working at the bench (reproduced with permission from Yaskawa Electric Corporation). 
(Electronic Medical Records and Genomics) Network in 2007 to fund research that combines DNA biorepositories, electronic medical records and genetic research [77]. This multi-institutional collaborative explores the use of genetic variation data into genetic risk assessment, prevention, diagnosis and treatment of disease. In addition, healthcare centers such as Memorial Sloan-Kettering Cancer Center are partnering with sophisticated information technology resources such as IBM's Watson supercomputer to develop novel methods of diagnosing and treating disease [76].

It is interesting to note that the utilization of computing power has gone through stages. In the 1970s, the use of telephone wires to communicate data to a central computer was the model. Also, typewriters and punched paper tape played a prominent role in the process [17]. By the 1990s, desktop computers or computers embedded in or adjacent to analyzers had become commonplace. Now, in 2014, we have a combination of portable devices, desktop computers and workstations all working in conjunction with centralized servers or cloud-based services.

Artificial intelligence currently is used extensively. Some examples include result interpretation via auto-verification programs, testing algorithms that reflex to separate orders based on initial results, and interpretations based on unifying the results of multiple tests (e.g., gene signatures) [78]. In addition, voice recognition is commonly used in anatomic pathology practice [79].

As anticipated, data encryption has assumed considerable importance, especially in the context of safeguarding electronic health information in the cloud [80]. Improved computational power has not only enabled interpretation of genomics data, but has also revealed the possible difficulties in ensuring privacy of genetic information. Recent studies have demonstrated the power of comparing genetic information, surname and other personal identifiers to deduce the identity of a sequenced individual [81].

Predictions about the development of data banks also proved to be correct. Today there are numerous genetic and protein data banks accessible via the internet (e.g., GenBank, dbSNP, HGMD, ClinVar, The Protein Data Bank) [82-84].

Enthusiasm for implantable radio-frequency identification (RFID) microchips was well placed. In 2004, the FDA approved the VeriChip implantable RFID device [85]. Unfortunately, the VeriChip was discontinued in 2010 due to lack of commercial success. Other RFID tags have been better received and are used to tag patient specimens (blood tubes, tissue cassettes, identifying wristbands) [86] and components of analyzers and automation systems (e.g., Gen-Probe fluid containers, Beckman Coulter pucks) $[87,88]$.

Based on the advances over the last fifty years, we almost certainly can predict that computing power, memory capacity, networking and portability will improve. In fact, Moore's law has successfully predicted the doubling of data approximately every 18 months [Moore's law]. These hardware advances, together with innovative software, will enable further miniaturization of analytical devices, create new analytical tools for quality control, and also create new tools for predicting future health based on current medical information [89].

One emerging computer-enabled technology is 3D printing that can be used for rapid manufacturing of a three-dimensional object. This facilitates distributed manufacturing and has the potential to cause a sea change in the way in which equipment and consumables are sourced by clinical laboratories in the future [90].

As computing becomes more routine, there will need to be heightened awareness of errors that potentially put patients at risk. The risk of undetected mistakes will grow as algorithms and processes become more complex and automated. Indeed, a recent scandal involving faulty diagnostic expression profiling (revealed by a forensic bioinformatic study) [91,92] has resulted in recommendations from the Institute of Medicine (IOM) on future test development and implementation [93]. The IOM investigation concluded that complex technologies have errors that are either unintentional (mistakes) or intentional (fraud) that are difficult to detect or control.

\subsection{Analytical techniques and technologies}

Several authors have made generalized predictions regarding the future of analytical techniques and technologies (Table 1). These include new types of toxicological assays, new tests for the management of cancer and central nervous system disorders, increased number and specificities of immunological analytes, more functional analyses, development of less-complex tests, advances in cellular diagnostics, image analysis and immunocytometry, and intracellular metabolic studies based on fine needle biopsies and fluorescence-activated cell sorting (FACS) [26-28,40]. A few specific methods have been singled-out as important in terms of the future of laboratory medicine such as nonisotopic immunoassays, HPLC-based analyses, tandem mass spectrometry (MS), GC-MS-based assays, nuclear magnetic resonance microscopy (NMR) (cellular metabolo-imaging) and cell sorting $[33,36,46]$. In addition, the laboratory of the future has been envisioned to have more standardized methods (e.g., standardized immunological measurements) [27].

In vivo assays also have been identified as an attractive future analytical direction. Some examples are in vivo nuclear magnetic resonance spectroscopy, imaging with antibody fragments, blood gas testing, oximetry and bilirubin measurements, endomicroscopy, optical coherence tomography and smart medical implants using biosensors and fuel cells (active real-time autonomous monitoring) [28,40].

Noninvasive testing is a long-cherished goal. Future prospects have included noninvasive instrumentation and an expanded role for noninvasive diagnosis (e.g., nuclear magnetic resonance of whole body or organs, probes for the mouth and other body cavities) [26,28].

Predictions related to an increase in the type of tests have been a safe bet (e.g., new types of toxicological assays, new tests for the management of cancer and central nervous system disorders). Likewise, predictions about the growth of non-isotopic immunoassays, HPLC-based analyses, GC-MS-based assays have been correct. Technologies that have been integrated into current clinical practice include intracellular metabolic studies (based on fine needle biopsies, FACS) and nuclear magnetic resonance microscopy (NMR) (cellular metabolo-imaging, ${ }^{1} \mathrm{H}-\mathrm{NMR}$ metabolonomic profiling of cancer tissue) [94]. Smart medical implants also have become a reality, as exemplified by the Guardian system for real-time continuous monitoring of glucose via an embedded sensor in a thin needle placed under the skin [95].

Noninvasive testing has made some, albeit slow, progress. Infra-red (IR)-based methods for oxygen determination are now commonplace (e.g., pulse oximetry), noninvasive multiple wavelength reflectancebased bilirubin measurement in neonates has become established in clinical practice (SpectRx BiliCheck) [96], and nuclear magnetic resonance probes for body cavities (e.g., rectal probes) have been developed to image the prostate [97]. There also has been an emergence of novel sources for biomarkers such as saliva and breath testing (e.g., Metabolomx breath test for lung cancer based on volatile organic compounds) [98].

Another issue related to emerging technologies is the sudden intervention by a regulatory agency. A case in point is direct-to-consumer genetic testing (e.g., 23andMe). Initially, this type of testing flourished, but the FDA determined that 23andMe was "marketing the 23andMe Saliva Collection Kit and Personal Genome Service (PGS) without marketing clearance or approval in violation of the Federal Food, Drug and Cosmetic Act" and that it must "discontinue marketing the PGS until such time as it receives FDA marketing authorization for the device" [99]. The FDA action against 23andMe is a reminder that regulators manage a balance between safety and innovation. Sometimes this balance will tip toward loose regulatory policy to foster innovation. However, in the interest of public health and/or safety, regulatory policy may tighten and inadvertently stifle innovation. Most recently, the FDA has issued a draft guidance to register and actively regulate laboratory developed tests (http://www.fda.gov/downloads/MedicalDevices/ ProductsandMedicalProcedures/InVitroDiagnostics/UCM407409.pdf). 
If this guidance is passed without major changes, it may dramatically change the development of esoteric tests in the United States.

A potential threat to many analytical methods is interference by hemoglobin in blood substitutes. If widespread clinical use of blood substitutes becomes a reality, the associated interference will render current chemistries inoperable. A possible solution would be to transition from UV-visible-based methods to IR-based analytical methods, as hemoglobin is transparent in the IR. IR-based methods for common chemistry analytes already exist [100]; however, the extent of hemoglobin interference in clinical specimens has not yet reached a critical level that would necessitate a change in methods.

A more distant analytical prospect is noninvasive testing for a broader range of analytes. This is a long-held goal but the ultimate prize of an effective noninvasive glucose monitor remains elusive. Nevertheless, noninvasive glucose testing, despite numerous setbacks, continues to be the focus of much research [101].

\subsection{Point-of-care testing}

Many views of the future of laboratory medicine include a trend toward more testing at the point-of-care (or near to the patient), greater integration of point-of-care testing into patient management strategies and pathways of care, and more testing in the home [44]. The recent growth in point-of-care testing has been facilitated by low-cost, portable, simple and flexible hand-held devices with built-in quality control systems and very broad menus. Specific predictions point to handheld devices for monitoring the top eight infectious pathogens [46]. In terms of ease of operation, one described target user is the "sleepdeprived surgeon"; therefore, one important goal of method development is ease of use [19].

A trend toward more testing at the point-of-care has been a safe bet as has the trend toward more testing in the home. Although the predicted point-of-care device for monitoring the top eight infectious pathogens is still not available, currently there are simplistic devices (for doctor's office or hospital use) that can detect $>20$ of the most common respiratory viral pathogens within hours (e.g., BioFire FilmArray) [102].

Many of the analytical systems used in the clinical laboratory have corresponding portable applications (electrolytes, hematology, blood gas, immunoassay, molecular diagnostics, flow cytometry, mass spectrometry) that can be used at the point-of-care. Limitations for widespread use of these devices are analytical reliability, cost, convenience and regulatory approval.

The rate of development of point-of-care devices is such that novel analytical technologies have the potential to decentralize laboratories. For example, if the cost of specific point-of-care tests, such as available on iSTAT, decreased to that of core-laboratory testing, the devolution of testing from the central laboratory to the point-of-care might occur rapidly.

One category of testing device that continues to advance is the wearable device. Two important examples of wearable wireless sensors include the Google contact lens for glucose testing [103] and the Triggerfish contact lens for monitoring glaucoma [104]. Other wearable sensors exist in the form of clothing (intelligent textiles) [105] or a tattoo (smart tattoos for glucose testing) [106].

Yet another type of wearable device is a watch. The GlucoWatch is an early example of a watch-like device designed to measure glucose [107]. Recently, Samsung announced a smart watch that will monitor vital signs [108]. Stand-alone modules, such as the Scanadu Scout vital sign monitor, are poised to influence the scope of testing in the home [109]. The slogan for the Scanadu device is "Check your health as easily as your email," which perhaps targets a generation of consumers that has grown up with computers, the internet, smartphones and tablets. Interestingly, the inspiration for many of these types of devices can be traced to the Star Trek Tricorder, an example of life imitating art.

Phones can perform analyses at the point-of-care using plug-in modules that take advantage of the computing and communication features of a computer. In the mid-2000s, there were cell phones modified by the addition of a reader (e.g., LG KP8400 phone with blood glucose monitor, and the GlucoPhone) [110]. Subsequently, the glucose meter component evolved into a USB stick-like device that could plug into the USB port of a computer (e.g., CONTOUR NEXT USB, Bayer) [111]. Most recently, the meter component plugs directly into the adapter port of a smartphone or tablet (e.g., iBIGStar connects to any Apple iOS device) [112].

Contrary to many predictions, hand-held devices in the form of smartphones and tablets are only slowly entering the mainstream of healthcare. However, there has been growing enthusiasm for phone devices that take pictures of slides and tissues, perform colorimetric tests, and readily provide on-board data analysis. Indeed, smartphones have become a platform technology perfectly suited for low-resource or remote settings within health networks [113].

The evolution of telecommunications, portable devices and smartphones has changed what is possible in low resource settings. Fifteen years ago, there was a focus on low resource infectious disease testing (e.g., tuberculosis). At the time, microscopy for examining sputum samples for acid-fast organisms was difficult in low resource settings because it required staining equipment, a microscope, and a skilled microscopist. This need was met by the successful development of molecular devices such as the Cepheid cartridge-based system for Mycobacterium tuberculosis [114]. In current times, smartphones can be enabled with simple adaptors to become powerful microscopes with submicron resolution that can detect single viral particles [115]. Images obtained from either a conventional or smartphone microscope can be sent via a smartphone app for remote viewing and interpretation by a pathologist (The UPMC Pocket Pathologist App) [116]. Thus, in a low resource setting, an alternative to sophisticated molecular diagnostic devices may be minimally skilled providers who require only an enhanced smart phone and a reliable method to process a sputum sample and take a picture. Continuing innovations in telecommunications and portable devices may one day render even the most sophisticated laboratory-based technologies obsolete.

\subsection{Telemedicine}

Telemedicine and telepathology, which are the practice of medicine facilitated by digital transmission of data, feature in a number of predictions for the future of laboratory medicine $[42,46]$. Aspects of internetenabled telemedicine include remote-controlled microscopy (linked to artificial intelligence) and remotely accessible telepathology workstation platforms. A European consortium is envisaged to bring together public and private laboratories to develop vital sign technology (telemedicine) [46]. Telemedicine-related predictions also focus on a smartphone or a tablet device; these types of devices are predicted to become the hub of medicine in the future [48].

In the United States, the military was an early adopter of telepathology and remote pathology [117]. Telepathology is now in place in many clinical laboratories [118]. In addition, dedicated home systems for both the collection and transmission of medical data from wireless devices are available from a number of companies (e.g., Viterion TeleHealthcare 100 BGM TeleHealth Monitor [119], Phillips TeleStation [120]). These types of systems collect and transmit a range of vital signs including blood pressure, pulse, blood oxygen, weight, temperature, and blood glucose.

The use of telepathology for the manual interpretation of differential blood counts has become routine with systems such as CellaVision DM1200, which scan and facilitate the interpretation of blood smears [121]. CellaVision represents a successful model for telepathology: (i) there are multiple sites with automated slide preparation and slide scanning, (ii) images are loaded into a centralized or cloud-based server and (iii) interpretation by laboratory professionals and physicians occurs from any internet-accessible location. The use of telepathology in routine surgical pathology has not yet occurred, but scanning systems 
that convert pathology slides into digital images are now common place for teaching, research and consultative practices. In addition, although digital slide scanning systems for primary diagnosis of surgical pathology have not yet gained regulatory approval in the United States, slide scanning systems for primary pathology diagnosis have gained regulatory approval outside the United States. The prediction that a smartphone, tablet or other portable device can become the hub of medicine has become a reality with real-life examples of doctor-patient encounters, static image examination and whole slide imaging.

The advantages of telehealth include reduction in hospital readmissions, improved clinical outcomes and reduction in long-term health costs. These are sufficiently compelling to make telehealth an important component of the future of health care. Also, it is expected that emerging smartphone telehealth applications will develop alongside the home station technology.

Two key regulatory guidances provided by the US FDA have created clear paths for the clinical implementation of digital pathology (slide digitization, accessing and interpretation) and medical software on portable devices (mobile medical apps) [122,123]. Although the initial reception has been tepid from proponents of these technologies, the pathway to commercialization has become much clearer. It is inevitable that these imaging systems will enable slide interpretations across wide geographic areas. Indeed we can anticipate that this will enable further consolidation of surgical pathology testing and interpretation. Indeed, the major anticipated obstacles to remote interpretation will be regulatory issues such as medical licensure [124]. Issues of interstate licensure

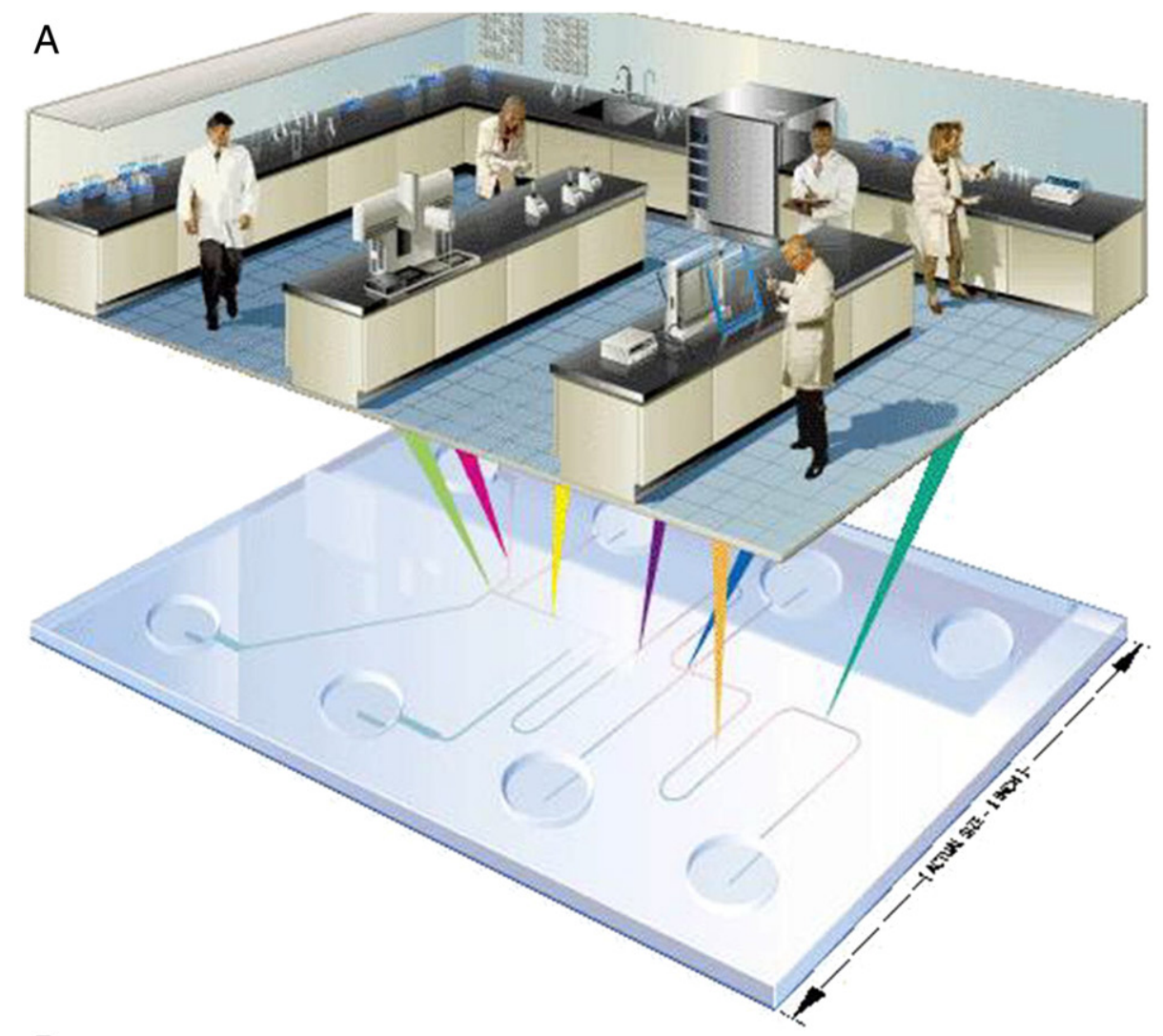

B

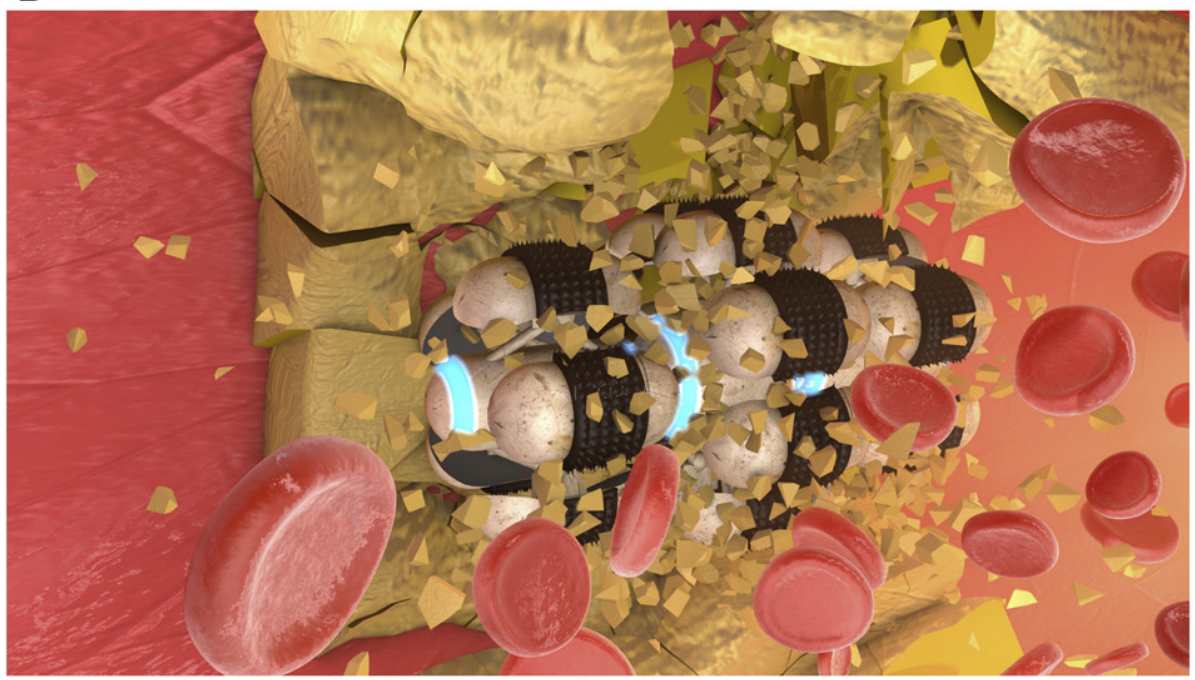

Fig. 3. A. The lab-on-a-chip concept (@ 2006-2014 PerkinElmer, Inc. Reproduced with permission). B. Nanorobot for atherosclerosis plaque removal in vivo (reproduced with permission Nanobotmodels Medical Animation, Svidinenko Yuriy - www.nanobotmodels.com). 
in the United States are being anticipated by the development of a proposed interstate licensure compact [125].

\subsection{Microtechnology}

The technological advances that accompany the miniaturization of analytical devices are a dramatic change from the traditional analytical techniques used in laboratory medicine $[23,126]$. The focus of microtechnology has been on "lab-on-a-chip" devices (Fig. 3A). Some examples of these include chips for specimen identification (e.g., incorporates sample identification and patient record within the sample cuvette), semipermanent implanted personal profile chips for detection of disease signatures in peripheral blood, high-density antibody and protein chip arrays for immune disease testing, and DNA chips. Microchips and micromachines assembled using micro-electromechanical (MEMS) technologies are predicted to transform analytical instrumentation [27].

Miniaturized analytical devices, e.g., "lab-on-a-chip" devices, have not lived up to their hype and relatively few have found routine use in clinical analysis. Exceptions include DNA arrays (e.g., Affymetrix arrays, Illumina bead arrays) $[127,128]$ and protein array chips [129]. The more futuristic vision for specimen identification chips that incorporate sample identification and the patient record within the sample cuvette has not reached fruition.

The scope and extent of research on microminiaturization, microfluidics and total integration of assays onto a chip is enormous, and it is difficult to believe that this ultimately will not yield a large number of analytically useful devices. However, the emergence of noninvasive techniques could herald the decline of devices that rely on a sample. In the absence of such a paradigm shift, some notable current developments focus on the combination of reagent-coated microbeads and arrays of reaction vessels, especially in the context of single molecule counting (digital) immunoassays and PCR. This type of technology underlies an emerging generation of ultrasensitive immunoassays that can detect proteins present at ultralow levels [130].

\subsection{Nanotechnology}

The analytical advantages that might be realized from miniaturization at the nanometer scale have captured the imagination of many prognosticators [41]. Applications include nanoparticles that seek out specific cells and analytical systems for single cell analysis [44,46]. More futuristic visions include diagnostic nano-robots for monitoring of disease [46] (Fig. 3B).

Nanotechnology has not had as large of an impact on diagnostics as was predicted. The futuristic vision of diagnostic nano-robots for disease monitoring was originally proposed in 1959 by Albert Hibbs [131]. This general idea is embodied in the recently developed "Bacteriobot" that is a genetically modified, non-toxic, motile salmonella bacterium armed with sensors to detect chemicals released by cancer cells [132]. Practically, nanoparticles as labels or solid phases (e.g., for capture antibodies or probes) provide the largest area of application (e.g., 13-20 nm reagent-coated particles used in the Nanosphere Verigene System) [133].

Nanotechnology is the subject of a large and diverse range of research; therefore, it is expected that nanotechnology ultimately will have a major impact on analytical methods. Innovations in nanotechnology have produced a diverse range of nano-sized objects with analytical utility including nanoparticles (quantum dots), nanofibers, nanowells, nanopores, nanorods, nanotubes, nanoprisms, nanochannels, and nanowires. Nanostructured materials also are beginning to find analytical uses (e.g., nanostructured magnesium oxide-chitosan for genosensing) [134]. However, safety-related concerns have surrounded the manufacture and implementation of nanomaterials, especially carbon nanotubes. This may hinder the future use of some nanomaterials [135].

\subsection{Genomics}

In general, many predictions for the future of laboratory medicine highlight the importance of molecular diagnostics and the integration of molecular medicine, information and computer technology. The emergence of toxicogenetics and pharmacogenetics, in the context of preventative medicine, had been predicted as early as 1969 [16]. Subsequently, genomics (e.g., pharmacogenetic and pharmacogenomic testing and profiling) has been featured in a number of views of the future, especially in the context of facilitating individualized drug-dosing regimens. The use of pharamacogenetic information to guide therapeutic decisions (theranostics) is predicted to become a significant portion of healthcare [117]. One view of the future envisions that both large pharmaceutical companies and private laboratory services will provide pharmacogenomic and metabologenomic services in the home [46].

Methodology-based predictions focus on viral load monitoring, high-density SNP diagnostic assays (e.g., for profiling tumors), neonatal genetic screening, twenty-four color chromosome karotyping/spectral analysis (e.g., hematological malignancies and solid tumors), widespread use of DNA probes, electrochemical detection of infectious agents, gene mutation analysis, gene and protein profiling using devices in a primary healthcare setting, and quantitative amplification technology on easy-to-use instruments. In addition, the completion of the human genome project is predicted to fuel the development of hundreds of possible new diagnostic tests [40].

A key component of genomics is sequencing technology. In 1988, Leroy Hood proposed that the first phase of technology development would take 5-10 years, and that sequencing of the human genome would take between 10 and more than 20 years to complete [38]. More current prognostications believe that the number of individuals who have had their genome sequenced will increase in the future, and individual patient genome signature profiling will become commonplace.

In the area of genomics, incorrect estimates for the number of genes and the function of DNA have misinformed predictions. The original estimate for the number of genes in the human genome was 6.7 million, a far cry from the current estimate of approximately 20,000 genes [136]. Likewise, the discovery that "junk" or "non-coding" DNA maintains functionality has transformed DNA sequencing and interpretation efforts [137]. It seems reasonable to expect that junk DNA will be a rich source of discovery that will have a significant impact on molecular diagnostics in the future.

Predictions overestimated the time it would take to complete the sequencing of the human genome. The original US Department of Energy and the National Institutes of Health $\$ 3$ billion project was founded in 1990 and expected to take 15 years. In reality, the draft sequence was completed in June 2000 , followed by the publication of a working draft in 2001 [138]. In general, predictions about the importance of the human genome project and molecular diagnostics have been correct.

Over the past decade, the emergence of next-generation/massivelyparallel sequencing has revolutionized DNA sequencing [139]. For now, the clinical applications of large-scale sequencing have been limited to the testing of rare diseases and tumors for the off-label use of drugs.

As predicted high-density SNP diagnostic assays have become commonplace. The first FDA-cleared microarray system was the Amplichip Cytochrome P450 genotyping test (Roche-Affymetrix) [140]. This system detects 31 DNA variants in the cytochrome genes CYP2D6 and CYP2C19. In 2014, the FDA cleared the Cytoscan HD high density SNP array (Affymetrix) for use in the diagnosis of developmental delay, intellectual disability and congenital anomalies [141].

Other examples of specific tests and methodologies that are now common in clinical use include viral load monitoring (e.g., HIV, CMV, $\mathrm{HPV}$ ), DNA probes, neonatal genetic screening, and quantitative amplification technology on easy-to-use instruments (e.g., GeneXpert) [140]. The predicted twenty-four-color chromosome karotyping/spectral analysis (e.g., hematological malignancies and solid tumors) now exists 
[142], as does nucleic acid-based electrochemical detection of infectious agents [143]. Both are limited in their routine application.

Home genetic testing services (from either pharmaceutical companies or private laboratories) have not been developed. The closest analogy would be some of the direct-to-consumer tests (e.g., 23AndMe SNP testing) [144]. We also have not arrived at a future in which large numbers of individuals have had their genome sequenced and individual patient genome signature profiling has become commonplace. As of June 2012, there were only 69 complete human genome data sets publicly available [145]. However over a million more are currently planned (UK 100,000 genome project [152] and the BGI one million human genomes project [153]).

Pharmacogenomic testing has been implemented slowly over the past decade. An increase in consumer demand may drive utilization in the primary care setting. The predicted provision of pharmacogenomic services is now a reality. Express Scripts, the largest pharmacy benefit manager in the United States, has a personalized medicine program that identifies patient eligibility for specialty drugs based on genetic testing. Indeed, this new model of personalized medicine utilizes the pharmacist to interpret genetic results to determine pharmaceutical selection $[55,146]$. The use of pharmacogenetics to guide individualized drug selection and dosing has been controversial and has not reached wide adoption. One exception is drug selection in the context of targeted therapy in oncology - this has become readily adopted in the past decade and is expected to grow. Unfortunately, there are few examples of sustainable remission on targeted therapy.

The use of genomic methods, such as expression profiling, has had limited success. In the 1990s, there was a NCI director challenge to replace histological interpretation and classification of tumors by RNAexpression profiling methods on DNA microchips (Fig. 4). Subsequently, there have been some tremendous commercial successes by companies, such as OncotypeDX [147], that offer RT-PCR based profiling of multiple mRNA markers to predict future risk of breast cancer recurrence and determine additional adjuvant chemotherapy. Agendia (MammaPrint) is another example of a company that has commercialized tumor profiling [148]. The FDA responded to the development of these types of complex multimarker tests with guidance known as IVDMIA (In Vitro Diagnostic Multivariate Index Assay). Although the guidance was drafted in 2007, it is still not finalized 7 years later [149], and not all clinically available expression profiling tests have complied with IVDMIA. Expression profiling certainly has not replaced histologic diagnosis and traditional cancer classification systems, but has become an ancillary test to guide therapy. Indeed, a recent medical research fraud case has resulted in an IOM investigation and guidance for further regulation of complex tests such as expression arrays [150].

In 1969, Whitehead described the evolution of clinical chemistry through several eras of development [16]. The development of other diagnostic testing such as genetic testing has undergone similar phases of development as illustrated in Table 1 . A new era to consider, which was not anticipated, is one of commoditization. In this new era, testing is considered routine and laboratory management and cost containment are key drivers.

It seems that pharmacogenomics will continue to struggle to maintain relevance in the future. Poor adoption, even in the context of clinical benefit, suggests that unless there are external pressures, this type of testing will not increase. However, the implementation of personal credit card-sized pharmacogenetic profile cards illustrates one way in which pharmacogenomics could evolve in the future (Fig. 5).

Next-generation sequencing will make DNA testing readily available, but we are still in the early implementation phase of this technology, and its clinical utility remains questionable [151]. Several large clinical studies are anticipated to provide insight into the link between
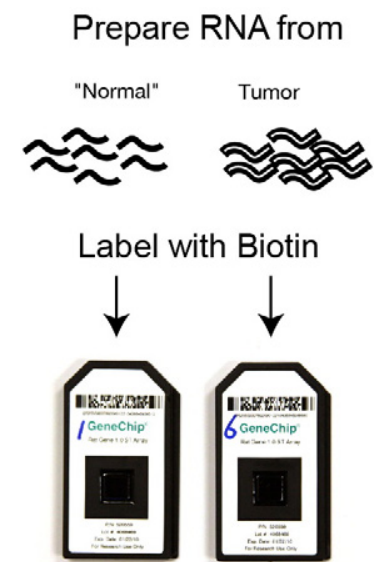
A

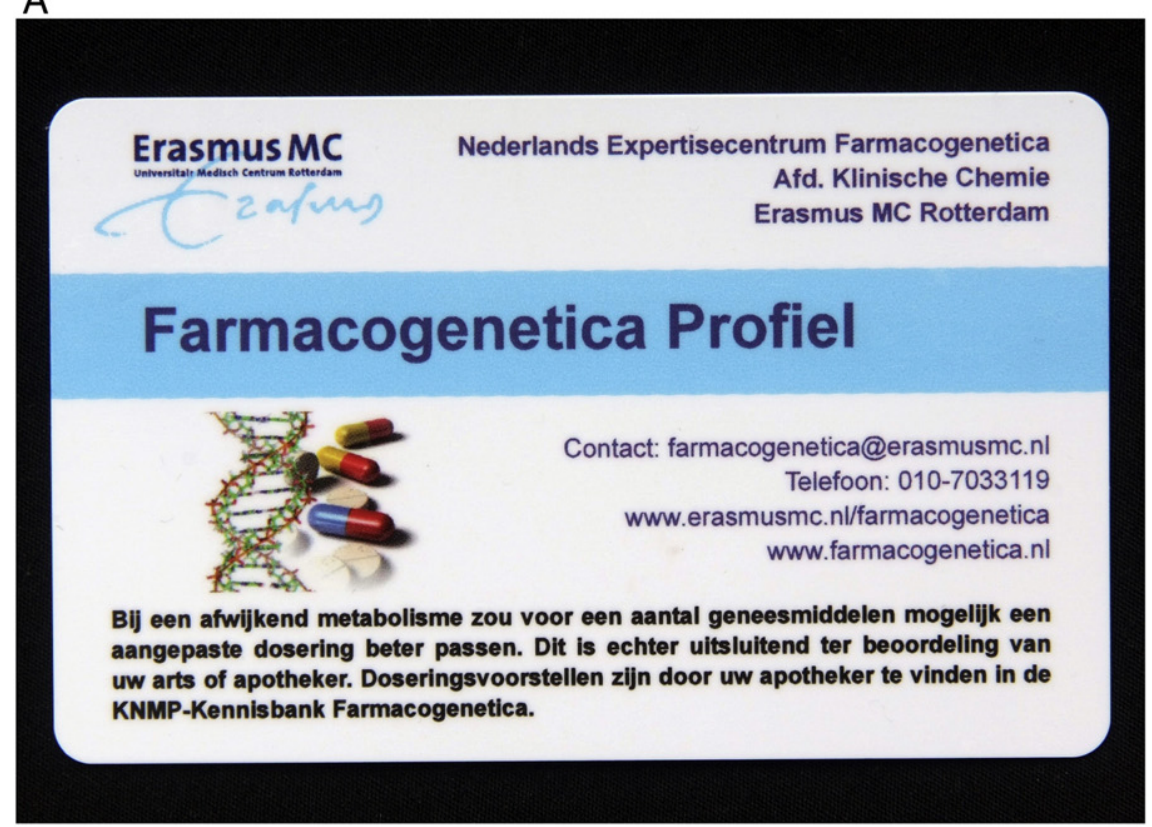

B

\begin{tabular}{|c|c|c|c|c|}
\hline \multicolumn{3}{|c|}{$\begin{array}{l}\text { Naam: Test Erasmus MC/RvS } \\
\text { BSN: } 12345678\end{array}$} & \multicolumn{2}{|c|}{$\begin{array}{l}\text { Geb. datum: 01/01/1980 } \\
\text { Uitgifte kaart: 14/07/2014 }\end{array}$} \\
\hline Gen: & Uitslag: & Metabolisme & Prev.: $^{1}$ & Getest op: \\
\hline CYP1A2 & $* 1 /{ }^{* 1}$ & Normaal & $45 \%$ & $* 1 \mathrm{C},{ }^{*} 1 \mathrm{~F},{ }^{*} 1 \mathrm{~K}$ \\
\hline CYP2B6 & $* 4 / * 6$ & Intermediair & $25 \%$ & $* 4,5,6,7,8,9,13,16,18$ \\
\hline CYP2C9 & $* 1 / * 2$ & Intermediair & $17 \%$ & $* 2,3$ \\
\hline CYP2C19 & $* 1 / * 1$ & Normaal & $80 \%$ & $* 2,3,17$ \\
\hline CYP2D6 & $* 1 / * 2 \times N$ & Ultrasnel & $3 \%$ & 25 varianten (AmpliChip) \\
\hline CYP3A4 & $* 1 / * 1$ & Normaal & $80 \%$ & *1B,1G,3-6,10,12,17,18,20,22 \\
\hline CYP3A5 & $* 3 / * 3$ & Nonexpressor & $80 \%$ & $* 3, * 6$ \\
\hline BChE & $\mathrm{U} / \mathrm{S}$ & Normaal & $99 \%$ & A, K, F1, F2, H, J, Sc, Silent \\
\hline DPYD & $* 1 / * 2 A$ & Intermediair & $2 \%$ & $* 2 A$ \\
\hline HLA-B*5701 & NEG & Normaal & $96 \%$ & \\
\hline TPMT & $* 1 / * 1$ & Normaal & $89 \%$ & $* 2,3 \mathrm{~A}, 3 \mathrm{~B}, 3 \mathrm{C}$ \\
\hline VKORC1 & AA & Gevoelig & $20 \%$ & $-1639 G>A$ \\
\hline
\end{tabular}

Fig. 5. Personal credit card-sized pharmacogenetic profile card (images courtesy of Professor Ron van Schaik, Erasmus MC, Rotterdam, The Netherlands).

DNA sequence and disease. Two examples are the UK 100,000 genome project [152] and the Beijing Institute for Genomics (BGI) Million genome project [153].

A critical factor that will affect the future of genetic testing is the continued fall in the cost of sequencing (Fig. 6). In 2001, the cost per Mb was $>\$ 5000$. By October 2013, the cost had plummeted to $\$ 0.057$ [154]. The $\$ 1000$ genome had remained a futuristic goal that reached fruition in 2014 with the launch of the Illumina HiSeq X Sequencer [155]. At the current time, the HiSeq $X$ costs $\$ 10$ million per unit and can sequence a whole genome for $\$ 1000$ (when the capacity of 20,000 per year is met). As a theoretical consideration, every year in the United States, approximately 4 million newborns undergo genetic and/or metabolic screening tests for potentially harmful or fatal conditions [156]. If these newborns instead were tested by whole genome sequencing, we potentially could meet the national need for the vast majority of genetic testing using HiSeq X instrumentation. In fact, 200 HiSeq X instruments, each running 20,000 samples per year, could meet all of the newborn testing needs, although additional genetic testing may be necessary in a subset of the population (e.g., the selection of therapeutic modalities in patients that develop cancer). This "HiSeq X newborn screen" may seem to be an extreme approach with a price tag of $\$ 4$ billion per year. However, predictions by the US health insurer United Healthcare indicate that, by 2021, the United States will spend between $\$ 15$ and $\$ 25$ billion per year on genetic testing. A HiSeq X national infrastructure for newborn genomic sequencing may be a relative bargain.

Currently, a $\$ 1000$ genome does not include the costs of interpretation, long-term data storage and other infrastructure needs, but it is now a realistic number that is far cheaper than most complex genetic tests [157]. The subject of population genomic testing is no longer an analytical fantasy, but a reality that must be dealt with by society; society 


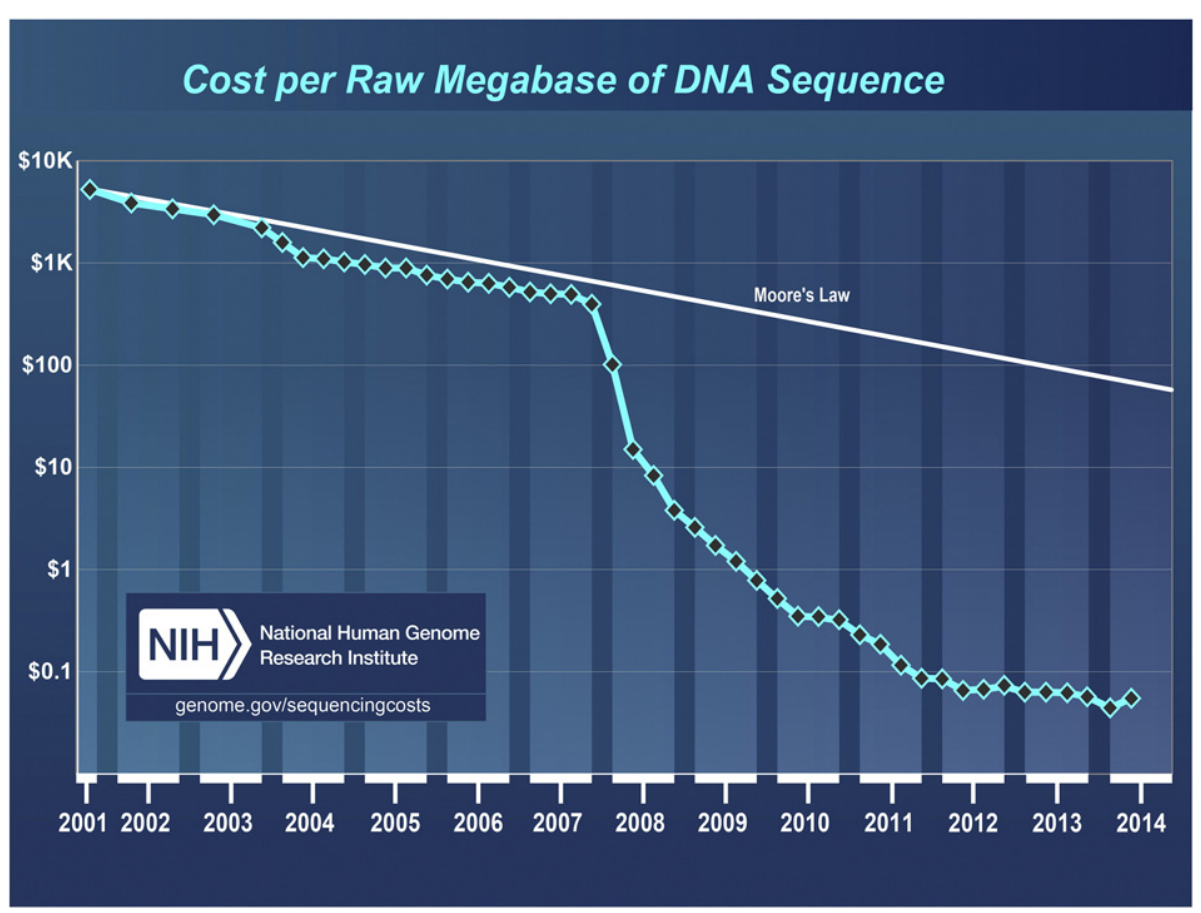

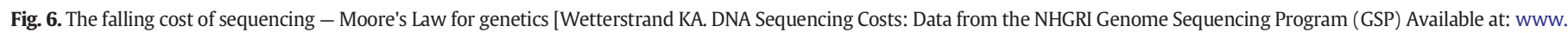
genome.gov/sequencingcosts. Accessed [July 2014]].

may not want this test outside of the context of disease treatment and management. The major remaining barriers to massive population sequencing include unresolved quality and regulatory and ethical issues.

There is more than one philosophical approach toward the future of whole genome sequencing: an optimistic perspective would be that whole genome and whole exome sequencing will have utility in healthy populations and will predict future health, while a pessimistic perspective would be that whole genome sequencing has limited application outside of ultra-rare pediatric diseases and will be limited to research applications. The current mainstream view on genomics is that the market is unlimited; all individuals potentially will have their genome sequenced at birth, and every patient with a new cancer diagnosis will have his tumor DNA and RNA sequenced and profiled.

\subsection{Proteomics}

Proteomics, similar to other types of "omics", is envisaged to provide the basis for future diagnostic tests. Predictions describe the development of analytical systems capable of testing for hundreds and thousands of different proteins. For example, mass spectrometry has been identified as a method to generate protein expression profiles [41].

One interesting foundation for the future of proteomics is the development of human molecular anatomy, based on the NIH-AEC Molecular Anatomy Program designed to dissect human cells at the molecular level. This was an ambitious goal that relied on high-resolution analytical methods such as two-dimensional electrophoresis (e.g., ISO-DALT). The Molecular Anatomy Program sought to catalog the complete set of proteins expressed in humans (The Human Protein Index), and hence, systematically explore gene regulation and misregulation [158].

In recent years, the varieties of "omics" have proliferated, and predictions regarding the importance of different types of omics, such as proteomics and genomics, have been well founded.

Diagnostic protein assays slowly have been added to the menu of routine tests (e.g., troponin I, BNP). In addition, the importance of mass spectrometry (MS) for generating protein profiles has been borne out by the new, recently FDA-approved, MS-based microorganism identification systems (e.g., BioMerieux VITEK MS system [159] and Bruker MALDI Biotyper CA [160]).

The total number of proteins in human cells is estimated to be between 250,000 and $1,000,000$ [161]. It is a reasonable expectation that many of these as yet unstudied proteins could be the basis of a new diagnostic test, either singly or as part of a multiplex test. Multiplex protein assays, in a two-dimensional planar array or a liquid (suspension) array format (e.g., collections of microbeads), continue to be the focus of attention and are expected to become more common if the protein signature approach to analysis continues to grow [162]. Detection remains a challenge for proteins present at very low concentrations. However, the new generation of digital immunoassays may provide the required technology $[130,163]$. The path forward for protein biomarkers and protein-based multiplex assays also has been improved by specific recommendations for the biomarker development, evaluation and validation process [164,165].

\subsection{Evidence-based medicine}

When combined with experience-based medicine, evidence-based medicine has been predicted to provide an effective route for diagnosis and treatment [44]. Laboratory testing represents the single-highest volume clinical activity and underpins much of clinical decisionmaking [166]. The role of evidence-based medicine is to provide the evidence base for the use of laboratory investigations in clinical practice.

The emphasis on the importance of evidence-based medicine has been well founded, and there has been sustained interest and activity in this field $[167,168]$. The National Institute for Health and Care Excellence (NICE) provides an example of evidence-based decision making in healthcare; this UK-based organization offers diagnostic guidance about various tests and diagnostic pathways (NICE Evidence Services) [169]. In the US, the CDC has developed programs in Evidence-Based Laboratory Medicine that are intended to "systematically identify, develop, and pilot test laboratory medicine evidence-based quality/performance measures to improve public health with measureable laboratory practices which are safe, timely, efficient, effective, equitable and patient-centered" [170]. 
Concern continues to mount over healthcare spending in the US. At $17.4 \%$ of the GDP in 2009 , this figure is considerably higher than health care spending in any other country [171]. Rising health care costs are not sustainable, and the evidence-based medicine approach, via identification of best practices, may be one way to improve healthcare and reduce costs.

\subsection{Microscopy and histopathology}

The future role of microscopic examinations clearly was emphasized as early as 1887 [12] and again re-emphasized in subsequent years [13]. More recent views of the future envisage the marriage of artificial intelligence, microscopy and nuclear magnetic resonance microscopy [46].

Tissue analysis using a microscope has continued to be a resilient technology, which has stayed relatively unchanged for hundreds of years. In the late 1990s, the demise of surgical pathology was predicted with the rise of expression profiling of tumors [172]. This did not happen. In fact, surgical pathology remains the dominant technology for the diagnosis and classification of cancer. Nevertheless, the emergence of digital pathology and whole slide imaging has the potential to change the practice of pathology by adding analytical tools and altering workflow and interpretation [173]. Automated imaging systems, such as FocalPoint and CellaVision, are commercial successes that have changed the workflow of clinical laboratories [72,121].

The predicted shortage of pathologists has not materialized, and the most recent workforce study indicates a current surplus - however, this is predicted to become a shortage in future years [174]. The pathologist workforce will change in parallel with the nature of the work to be done. For example, the autopsy is a key service traditionally performed by pathologists, but the number of autopsies performed has fallen in the United States (50\% decline from 1972 to 2007) [175]. This has been off-set by a concomitant rise in small tissue sampling such as fineneedle aspirations and endoscopic biopsies.

Digital pathology will increase the efficiencies of training and daily practice by enabling faster training of future pathologists. In addition, the digitization of slides holds the possibility of distributing workloads amongst multiple physical centers separated by state and national boundaries.

The Ontario Health Network is one model for the efficient deployment of surgical pathologists. In this model, there are centers of highly specialized pathologists in dense population areas in proximity to specialized centers of care. These specialized pathologists work in conjunction via digital pathology and telecommunication networks with more generally trained pathologists to cover a vast geographic area [176]. As digital pathology becomes routine, the workforce requirements for pathology are predicted to increase; however, efficiency will also increase as caseloads can be balanced between multiple geographic sites. Furthermore, the workforce will segment into generalists who maintain community hospitals and perform activities that cannot be done remotely (apheresis, fine needle aspirations, laboratory management) and specialists who sit in a communications center interpreting digital images and providing consultations to generalist pathologists and clinicians.

The Pap smear for cervical cancer screening has historically been a high volume test for pathologists and cytologists globally. With the advent of automated imaging systems, such as FocalPoint [72], there has been a decrease in the number of cervical Pap smears evaluated by humans. In addition to automation of standard Pap smears, recent clinical guidelines [177] have suggested that molecular HPV infection evaluation may substitute for microscopic examination of cervical cells. In 2014, the FDA approved the use of the Roche Cobas HPV test as a first line primary screening test for cervical cancer [178]. Furthermore, the implementation of HPV vaccination in the United States will decrease the rate of HPV infection and abnormal Pap smears that require evaluation.
Endomicroscopy [179] and high-field strength nuclear magnetic resonance (NMR) [180] have micron level resolution and are in clinical use globally. Although these methods have not replaced microscopy, further advances in these minimally invasive imaging tools may erode the need for microscopy of tissue specimens.

\section{Predictions for laboratory medicine in regions and countries}

In addition to the US, specific predictions and plans for the future of laboratory medicine have focused on other countries. In 1997, views on the future of the European Clinical Laboratory were explored by means of questionnaire answered by 31 national representatives [181]. The most frequently cited future challenges were implementation of request strategies, interpretative reports and pre-analytical aspects of analysis. The survey also revealed that respondents believed that information technology and new scientific developments would make the greatest impact, and that, in the future, economic pressure would be a major limiting factor on the activities of laboratories in spite of an anticipated increase in the number of tests.

In 2009, the Royal Belgian Society of Clinical Chemistry noted that hospital laboratories are being endangered by an increasing trend to outsource clinical laboratory tests to external laboratories [182]. It advocated proactive measures to increase efficiency and reduce costs by consolidation (e.g., formation of regional networks). It also commented that laboratory staff should refocus their efforts to provide medical knowledge services to clinicians.

In England, a prescription for the future of pathology and laboratory medicine can be found in the Pathology Modernization Programme launched in 1999, and in the subsequent Carter review published in 2006 [183]. So far there has been limited progress toward the visions for the future of pathology and laboratory medicine formulated in 1999 (e.g., managed pathology networks) or in 2006 (e.g., stand-alone pathology service providers, end to end IT connectivity including point-of-care testing).

\section{The future of laboratory medicine in the context of the future of medicine and healthcare}

Laboratory medicine exists within the broader framework of medicine and healthcare. Therefore, changes and advances in these areas will impact the future direction of laboratory medicine. Predictions made about medicine and healthcare, beginning in 1900 and reaching nearly 50 years into the future, are detailed in Table 2 [184-190]. The majority of the predictions are optimistic, and they predict more effective treatments, eradication of disease and a longer lifespan. Common themes in these futuristic visions are genetic testing and chips to facilitate real-time monitoring. For the period 2032-2062, a central role is predicted for telemedicine [186]. If these predictions are accurate, then the current rise in implanted sensors and telemedicine forebodes that central laboratory testing will play a lesser role in the future.

Others have identified megatrends in global health care [191] and innovations that will transform medicine [192]. The 12 megatrends are shown in Fig. 7. Finance and the management of limited resources are factors underlying many of the predicted trends [190]. Ten innovations identified in 2010 that were predicted to transform medicine in the future include: 1) checklists (e.g., strict protocols for procedures); 2) behavioral economics (e.g., peer pressure to change how doctors work); 3) patient portals (secure web connections for consumers to manage their health care); 4) payment innovations (schemes that reward good outcomes); 5) evidence-based decision making; 6) accountable care organizations; 7 ) regenerative medicine (e.g., stem cell-based treatments); 8) virtual visits (videoconferencing and remote monitoring); 9) genetics enters practice; and 10) surgical robotics [193].

A factor that is sure to have an impact on the future of laboratory medicine, and healthcare in general, is the aging population. The US Census Bureau projects that the population will rise to 420.3 million 


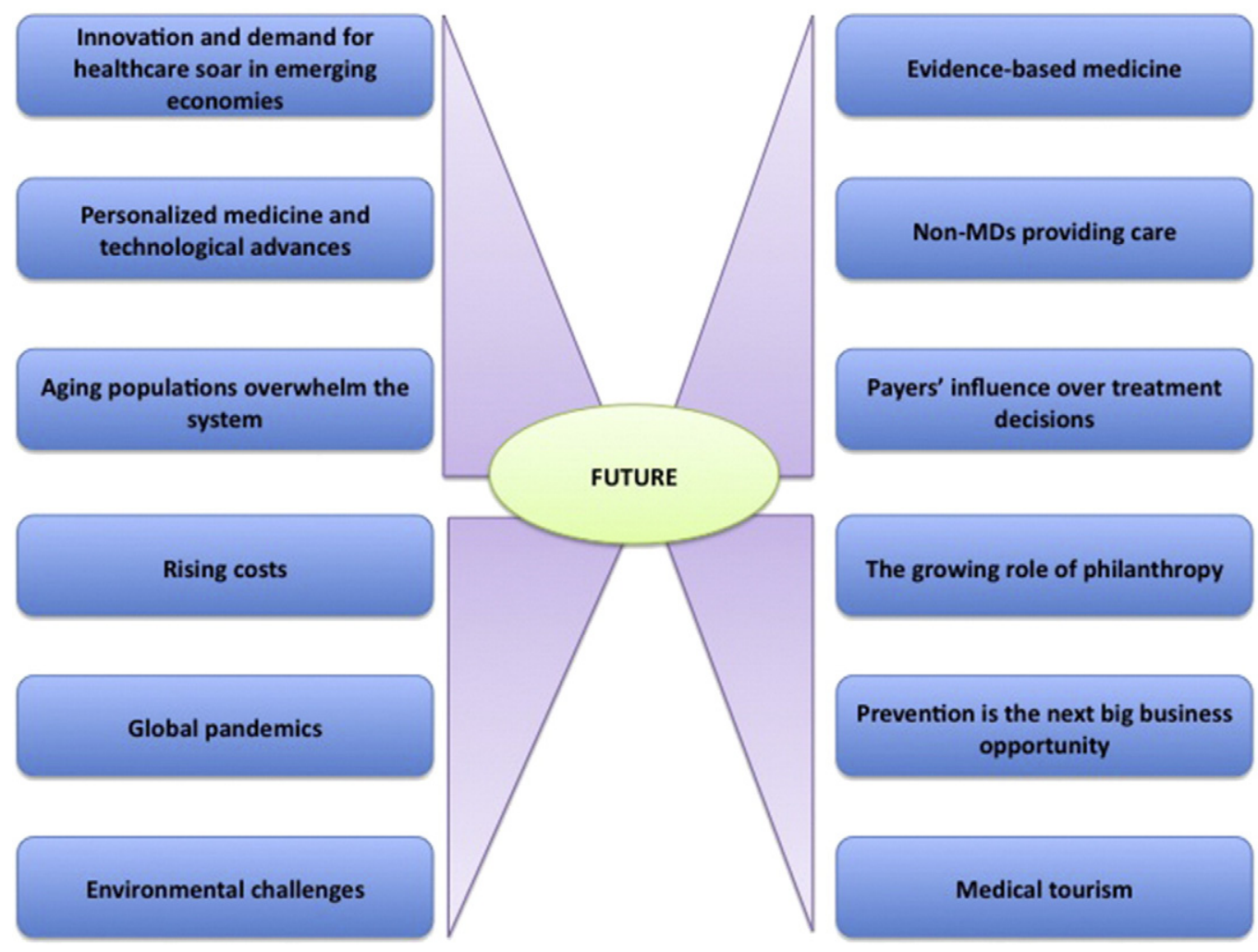

Fig. 7. Megatrends in global health care [191].

by 2060 , and that the percent of the population over the age of 65 years will be $22 \%$ (92 million) [192]. Linked to this is the long-term concern for the continuing growth of health care costs in the US, which are expected to reach $\sim 20 \%$ of GDP by 2021 [194].

Another current US concern is the likely impact of Accountable Care Organizations (ACO), which are groups of doctors, hospitals, and other health care providers that focus on the deliverance of cost-effective and high-quality care [195]. The economic pressures arising from these changes in healthcare financing and reimbursement also are anticipated to drive change in the clinical laboratory.

A change in healthcare strategy, such as embodied in P4 Medicine (Predictive, Preventive, Personalized, and Participatory Medicine), could impact the types of testing undertaken in the clinical laboratory. P4 medicine focuses on disease prevention and maintenance of health and wellness by applying systems biology to medicine [196,197].

Finally, unexpected disruptions could occur as a result of curing of chronic diseases. If 'cancer' were to be cured by a novel chemotherapeutic cocktail, then what services would be needed? Eradication of a chronic disease would lead to a dramatic reduction in the number of screening tests, diagnostic tests and monitoring tests. The same is true for diabetes. If type II diabetes could be treated in a way that did not require blood glucose monitoring, then there would be minimal need for point-of-care glucose testing. Conversely, the conversion of fatal diseases into chronic conditions would expand the need for testing services.

\section{Conclusions}

The predictions surveyed in this review provide insight into the changing views about the future of laboratory medicine and its subspecialties from 1887 to modern times. Making predictions is an inexact science, and so it is not surprising that many of the changes foreseen have not come to pass. However, prediction is nonetheless important because it is an integral part of the forward planning process that will shape the future of all aspects of laboratory medicine.

\section{Acknowledgments}

We thank the Executive Board of the International Federation of Clinical Chemistry and Laboratory Medicine (IFCC) for their encouragement in the preparation of this review in the context of the IFCC "Shaping the Future of Laboratory Medicine" initiative.

In addition, the authors would like to thank Mr. Svidinenko Yuriy, Nanobotmodels Medical Animation Studio, Ukraine; Mr. Kevin A. Oliver, PerkinElmer, Inc., Waltham, MA, USA; Mr. Darryl Leja and Kris Wetterstrand, National Human Genome Research Institute, Bethesda, MD, USA; Eric Mauk, Honda North America, Marysville, Ohio, USA; Mr. Tomohiro Matsuo, Yaskawa Electric Corporation, Mr Kevin Oliver, PerkinElmer; and, Professor R van Schaik, Erasmus MC, Rotterdam, The Netherlands, for providing images.

\section{References}

[1] Anon. The futurists: looking toward A.D. 2000. Time 1966;87:34-9.

[2] MarketLine. Online retail in the United States [internet]. [cited 2014 Aug 1]. Available from: http://www.marketresearch.com/MarketLine-v3883/Online-RetailUnited-States-7760207/; 2013.

[3] Hazelton L. "Next christmas the iPod will be kaput": how Sir Alan Sugar got it wrong 174 million times... and the web's other worst predictions. [Internet]. Daily Mail Online [cited 2014 Aug 1]. Available from: http://www.dailymail.co. uk/sciencetech/article-1093470/Next-Christmas-iPod-kaput-How-Sir-Alan-Sugargot-wrong-174million-times-webs-worst-predictions.html\#ixzz33Zqc0Eei.

[4] IBTimes. Apple's iPod turns 10: is the revolutionary MP3 player dying? [Internet]. [cited 2014 Aug 1]. Available from: http://www.ibtimes.com/apples-ipod-turns10-revolutionary-mp3-player-dying-361100.

[5] Lieberman D. CEO forum: Microsoft's Ballmer having a 'great time'. [Internet]. USA Today 2007 [cited 2014 Aug 1]. Available from: http://usatoday30.usatoday.com/ money/companies/management/2007-04-29-ballmer-ceo-forum-usat_N.htm.

[6] Techcrunch Kumparak G. Apple sold 14.1 million iPhones last quarter, over 70 million since launch [internet]. [cited 2014 Aug 1]. Available from: http://techcrunch. com/2010/10/18/apple-sold-14-1-million-iphones-last-quarter-over-70-millionsince-launch.

[7] Carr N. How many computers does the world need? Fewer than you think [internet]. . Wednesday The Guardian; Feb 202008 [[cited 2014 Aug 1]. Available from: http:// www.theguardian.com/technology/2008/feb/21/computing.supercomputers]. 
[8] File Thom. Computer and internet use in the United States. Current population survey reports, P20-568. Washington, DC: US Census Bureau; 2013.

[9] Randewich R. Global PC market shrank 11 percent in second quarter [internet] Reuters [cited 2014 Aug 1]. Available from: http://www.reuters.com/article/ 2013/07/10/us-technology-computers-idUSBRE9690ZA20130710; 2013.

[10] Gartner Inc. Gartner says worldwide PC, tablet and mobile phone combined shipments to reach 2.4 billion units in 2013 [internet]. [cited 2014 Aug 1]. Available from: http://www.gartner.com/newsroom/id/2408515. [Accessed July 2014].

[11] Gartner Inc. Interpreting technology hype [internet]. [cited 2014 Aug 1]. Available from: http://www.gartner.com/technology/research/methodologies/hype-cycle.jsp.

[12] Paget J. The future of pathology. Br Med J 1887;1:143-4.

[13] Dickinson WH. The past and future of pathology. Br Med J 1889;1:238-40.

[14] Conford GJ. The future of the medical profession. Br Med J 1906;2:1064.

[15] Addison C. Future provision of medical services. Br Med J 1920;29:739-43.

16] Whitehead TP. A view from a bridge. Ann Clin Biochem 1971:8:1-7.

[17] Donaldson FW. The doctor, medical laboratory and pharmacy on-line. Int J Biomed Comput 1970:3-9.

[18] Anderson NG. The future of clinical chemistry. Am J Med Technol 1978;44:233-7.

[19] Alberti KG. The clinical chemist and the future. Br Med J 1980;280:329.

[20] Hardwick DF, Morrison JI, Cassidy PA. Clinical laboratory - past, present, and future: an opinion. Hum Pathol 1985;16:206-11.

[21] Marks V. Impact of new technology on the future of clinical chemistry. Pure Appl Chem 1985:57:565-70.

[22] Burke DM. A different laboratory for the future. Clin Biochem 1986;19:274-6.

[23] Burtis CA. Advanced technology and its impact on the clinical laboratory. Clin Chem $1987 ; 33: 352-7$

[24] Benson ES, Anderson RE, Smith RD, et al. An impending shortage of community hospital pathologists. Hum Pathol 1989;20:405-6.

[25] Newman AR. The clinical chemistry laboratory of the future. Anal Chem 1990;62: $1063 \mathrm{~A}-5 \mathrm{~A}$

[26] Bock J. The future of clinical chemistry. Clin Chem 1990;36:821.

[27] Hamilton RG. The clinical immunology laboratory of the future. Clin Chem 1994 40:2186-92.

[28] Athena Society. The future of clinical chemistry and its role in healthcare: a report of the Athena Society. Clin Chem 1996;42:96-101.

[29] Wells IG, Farnan LP, Rayment MW. Client/server computing: is this the future direction for the clinical laboratory? Clin Chim Acta 1996;248:31-8.

[30] Kiechle FL. DNA technology, the clinical laboratory, and the future. Arch Pathol Lab Med 2001;125:72-6.

[31] Coile Jr RC. Clinical laboratory services' high-tech future. Russ Coiles Health Trends 2001;13(1):4-8.

[32] Ito RK, Demers LM. Pharmacogenomics and pharmacogenetics: future role of molecular diagnostics in clinical diagnostic laboratory. Clin Chem 2004;50:1526-7.

[33] Hicks JMB. Laboratory medicine: its future [internet]. [cited 2014 Aug 1]. Available from: http://wwwn.cdc.gov/cliac/pdf/Addenda/cliac0906/AddendumH.pdf; 2006.

[34] Bossuyt X, Vereire K, Blanckaert N. Laboratory medicine: challenges and opportunities. Clin Chem 2007;53:1730-3.

[35] Barth J. The future of laboratory medicine. , 151. Bulletin of the Royal College of Pathologists; 2010. p. 182-3.

[36] Melville RS. Future trends in clinical chemistry. Anal Chem 1977;49:594A-7A.

[37] Haeckel R. Future perspectives of automatization in clinical chemistry. J Clin Chem Clin Biochem 1980;18:455-9.

[38] Hood L. Biotechnology and medicine of the future. JAMA 1988;259:1837-44.

[39] Rosen S, des Ormeaux D. The clinical laboratory of the 2000s-a peek into the future. Can J Med Technol 1993;55:205-8.

[40] Hannan RE. The future of diagnostics. Genesis Rep 1995;4:28-30.

[41] Nakamura RM. Technology that will initiate future revolutionary changes in healthcare and the clinical laboratory. J Clin Lab Anal 1999;13:49-52.

[42] Wilkinson DS. The role of technology in the clinical laboratory of the future. Clin Lab Manage Rev 1997;11:322-30.

[43] Dwyer WM. Technology futures report. Abbott Health Systems Division; 1999.

44] Clarke W, Nichols JH. Future directions in clinical chemistry [internet]. Adv Adm Lab 2000;27 [[cited 2014 Aug 1]. Available from: http://laboratory-manager. advanceweb.com/Article/Future-Directions-in-Clinical-Chemistry.aspx]

[45] Hallworth M, Hyde K, Cumming A, Peake I. The future for clinical scientists in laboratory medicine. Clin Lab Haematol 2002:24:197-204.

[46] O'Leary JJ. Pathology 2026. The future of laboratory medicine and academic pathology. In: Hall PA, Wright NA, editors. Understanding disease. A centenary celebration of the Pathological Society. Chichester: John Wiley \& Sons; 2006 p. 217-31.

[47] Bartlett G, Antoun J, Zgheib NK. Theranostics in primary care: pharmacogenomics tests and beyond. Expert Rev Mol Diagn 2012;12:841-55.

[48] Komatireddy R, Topol E. Medicine unplugged: the future of laboratory medicine. Clin Chem 2012;58:1644-7 [(see Podcast [Internet]. [cited 2014 Aug 1]. Available from: at www.aacc.org/publications/clinchem/ClinChem_201212_topol.pdf)].

[49] Van 't Veer LJ, Dai H, van de Vijver MJ, et al. Gene expression profiling predicts clinical outcome of breast cancer. Nature 2002;415:530-6.

[50] Gustavson MD, Rimm DL, Dolled-Filhart M. Tissue microarrays: leaping the gap between research and clinical adoption. Personalized Med 2013;10:441-51.

[51] Beaudet AL, Belmont JW. Array-based DNA diagnostics: let the revolution begin. Annu Rev Med 2008:59:113-29.

[52] Yu X, Schneiderhan-Marra N, Joos TO. Protein microarrays for personalized medicine. Clin Chem 2010;56:376-87.

[53] Bielinski SJ, Olson JE, Pathak J, et al. Preemptive genotyping for personalized medicine: design of the right drug, right dose, right time-using genomic data to individualize treatment protocol. Mayo Clin Proc 2014;89:25-33.
[54] Moaddeb J, Haga SB. Pharmacogenetic testing: current evidence of clinical utility. Ther Adv Drug Saf 2013;4:155-69.

[55] Express Scripts. Personalized medicine [internet]. [cited 2014 Aug 1]. Available from: https://www.express-scripts.com/services/physicians/personalizedmedicine/

[56] Church DL, Hall P. Centralization of a regional clinical microbiology service: the Calgary experience. Can J Infect Dis 1999;10:393-402.

57] Scientistlive. Blood science platform consolidation increases effectiveness. www. scientistlive.com/content/250212.1.3; 2013

[58] Kibak P. The worsening shortage of lab staff [internet]. Clin Lab News 2008;34 [[cited 2014 Aug 1]. Available from: http://www.aacc.org/publications/cln/archive/ 2008/may/Pages/cover1_0508.aspx\#

59] Garcia E, Ali A, Choudhry S. The American Society for Clinical Pathology's 2012 vacancy survey of clinical laboratories in the United States. Lab Med 2013;44:e1-18.

[60] Jackson BR. Laboratory formularies. Clin Chim Acta 2014;427:151-3.

[61] Warren JS. Laboratory test utilization program: structure and impact in a large academic medical center. Am J Clin Pathol Mar 2013;139:289-97.

62] Liu Z, Abdullah A, Baskin L, et al. An intervention to reduce laboratory utilization of referred-out tests. Lab Med 2012;43:164-7.

[63] Feature story. Here or there? The urgency of 'physician first'. [Internet]. CAP TODAY March 2009. [cited 2014 Aug 1]. Available from:http://www.cap.org/apps//cap. portal?_nfpb=true\&cntvwrPtlt_actionOverride=\%2Fportlets\%2FcontentViewer\% 2Fshow\& windowLabel=cntvwrPtlt\&cntvwrPtlt \{actionForm.contentReference $\}=$ cap_today\%2F0309\%2F0309f_here_or_there.html\&_state=maximized\&_pageLabel= cntvwr

[64] Lab tests online [internet]. American Association for Clinical Chemistry. [cited 2014 Aug 1]. Available from: http://labtestsonline.org/.

[65] Parloff R. This CEO is out for blood [internet]. Fortune June 12 2014;170 [[cited 2014 Aug 1]. Available from: http://fortune.com/2014/06/12/theranos-bloodholmes/]

[66] Roper C. This woman invented a way to run 30 lab tests on only one drop of blood [internet]. Wired; Feb 182014 [[cited 2014 Aug 1]. http://www.wired.com/2014/ 02/elizabeth-holmes-theranos/].

[67] Constance JA. The worldwide market for lab automation. Kalorama Information; 2013.

[68] Honda. ASIMO. The Honda humanoid robot ASIMO [internet]. [cited 2014 Aug 1]. Available from: http://world.honda.com/ASIMO/.

[69] YASKAWA Report. Mahoro*: general-purpose, dual-arm robot as skilled researcher: 2013 11-2 [[cited 2014 Aug 1]. Available from: http://www.yaskawa.co.jp/en/ir/ir doc01.html].

[70] Herbek GN. Workforce issues affecting pathology. Confronting the issues surrounding the future of pathology and laboratory medicine workforce will require a team effort. Adv Lab Jun 2 2014;24 [[Internet]. [cited 2014 Aug 1]. Available from: http://laboratory-manager.advanceweb.com/Features/Articles/Workforce-Issues-Affecting-Pathology.aspx].

[71] Duran B, Thill S. Rob's robot: current and future challenges for humanoid robots. In: Zaier R, editor. The future of humanoid robots - research and applications. Rijeka, Croatia: InTech; 2012. p. 279-300.

[72] Wilbur DC, Black-Schaffeer WS, Luff RD, et al. The Becton Dickinson FocalPoint CS Imaging System. Clinical trials demonstrate significantly improved sensitivity for the detection of important cervical lesions. Am J Clin Pathol 2009;132:767-75.

[73] Carlson RP. Innovations in anatomic pathology lab automation [internet]. IVD Technol 2013;19(1) [cited 2014 Aug 1].

[74] Panteghini M. The future of laboratory medicine: understanding the new pressures. Clin Biochem Rev 2004;25:207-15.

[75] Modifications to the HIPAA pricacy, security, enforcement, and breach notification rules under the Health Information Technology for Department of Health and Human Services. Economic and Clinical Health Act and the General Information Nondiscrimination Act; other modifications to the HIPAA rules. Fed Regist 2013; 78:5565-702.

[76] Murdoch TB, Detsky AS. The inevitable application of big data to health care. JAMA 2013;309:1351-2

[77] Electronic Medical Records and Genomics (eMERGE) network [internet]. [cited 2014 Aug 1]. Available from: http://www.genome.gov/27540473; 2014

[78] Waldron L, Haib-Kains B, Culhane AC, et al. Comparative meta-analysis of prognostic gene signatures for late-stage ovarian cancer. J Natl Cancer Inst 2014;106(5) http://dx.doi.org/10.1093/jnci/dju049 [pii:dju049].

[79] Kang HP, Sirintrapun SJ, Parwani AV. Experience with voice recognition in surgical pathology at a large academic multi-institutional center. Am J Clin Pathol 2010 133:156-9.

[80] Rodrigues JPC, de la Torre I, Fernandez G, Lopez-Coronado M. Analysis of the security and privacy requirements of cloud-based electronic health records systems. J Med Internet Res 2013;15:e186.

[81] Gymrek M, McGuire AL, Golan D, Halperin E, Erlich Y. Identifying personal genomes by surname inference. Science 2013;339:321-4

[82] Benson DA, Cavanaugh M, Clark K, et al. GenBank. Nucleic Acids Res 2013; 41(Database issue):D36-42.

[83] NCBI. dbSNP. Database of single nucleotide polymorphisms (SNPs) and multiple small-scale variations that include insertions/deletions, microsatellites, and nonpolymorphic variants [internet]. [cited 2014 Aug 1]. Available from: http://www. ncbi.nlm.nih.gov/snp.

[84] Berman HM, Westbrook J, Feng Z, et al. The Protein Data Bank. Nucleic Acids Res 2000;28:235-42.

[85] Levine M, Adida B, Mandl K, Kohane I, Halamka J. What are the benefits and risks of fitting patients with radiofrequency identification devices? PLOS 2007. http://dx. doi.org/10.1371/journal.pmed.0040322. 
[86] Gillespie M, Mountain HM. RFID simplifies improvements to hospital bedside care [internet]. [cited 2014 Aug 1]. Available from: https://software.intel.com/en-us/ articles/rfid-simplifies-improvements-to-hospital-bedside-care; Mar 52012.

[87] Hologic Gen-Probe Inc. PANTHER system [internet]. [cited 2014 Aug 1]. Available from: http://www.gen-probe.com/products-services/panther-system.

[88] Beckman Coulter automation solutions. Power link [internet]. [cited 2014 Aug 1]. Available from: https://www.beckmancoulter.com/ucm/idc/groups/public/ documents/webasset/glb_bci_152591.pdf.

[89] IBM. The New York Genome Center and IBM Watson group announce collaboration to advance genomic medicine [internet]. [cited 2014 Aug 1]. Available from: http:// www-03.ibm.com/press/us/en/pressrelease/43444.wss.

[90] D'Aveni RA. 3-D printing will change the world [internet]. Harv Bus Rev 2013 [[cited 2014 Aug 1]. Available from: hbr.org/2013/03/3-d-printing-will-changethe-world/ar/1].

[91] Coombes KR, Wang J, Baggerly KA. Microarrays: retracing steps. Nat Med 2007;13: 1276-7.

[92] Baggerly KA, Coombes KR. Deriving chemosensitivity from cell lines: forensic bioinformatics and reproducible research in high-throughput biology. Ann Appl Stat 2009;3:1309-34.

[93] Spector J. IOM promotes 'roadmap' for genomics research. Comprehensive plan developed to 'do things right' in wake of scandal [internet]. Chronicle Mar 292012 [[cited 2014 Aug 1]. Available from: http://www.dukechronicle.com/articles/ 2012/03/29/iom-promotes-roadmap-genomics-research The Chronicle].

[94] Wang L, Chen J, Che J, et al. 1H-NMR based metabonomic profiling of human esophageal cancer tissue. Mol Cancer 2013;12:25. http://dx.doi.org/10.1186/ 1476-4598-12-25.

[95] Keenan DB, Cartaya R, Mastrototaro JJ. Accuracy of a new real-time continuous glucose monitoring algorithm. J Diabetes Sci Technol 2010;4:111-8.

[96] Robertson A, Kazmierczak S, Vos P. Improved transcutaneous bilirubinometry: comparison of SpectRX Bilicheck and Minolta Jaundice Meter JM-102 for estimating total serum bilirubin in a normal newborn population. J Perinatol 2002;22:12-4.

[97] Anderson CM, Hedgcock, Jr MW, Narayan P. Insertable NMR coil probe. US Patent 1992;5170789 A.

[98] Vance A. A machine that sniffs out cancer [internet]. Bloomberg Businessweek, 2012; Mar 01. [cited 2014 Aug 1]. Available from: http://www.businessweek. com/articles/2012-03-01/a-machine-that-sniffs-out-cancer

[99] US Food and Drug Admistration. Inspections, compliance, enforcement, and criminal investigations. 23andMe, Inc.; 2014 [11/22/13 [Internet]. [cited 2014 Aug 1]. Available from: www.fda.gov/iceci/enforcementactions/warningletters/2013/ ucm376296.htm].

[100] Synermed Inc. [internet]. [cited 2014 Aug 1]. Available from: http://www. synermedinc.com.

[101] Vashist SK. Non-invasive glucose monitoring technology in diabetes management: a review. Clin Chim Acta 2012;750:16-27.

[102] Popowitch EB, O'Neill SS, Miller MB. Comparison of the Biofire FilmArray RP, Genmark eSensor RVP, Luminex xTAG RVPv1, and Luminex xTAG RVP fast multiplex assays for detection of respiratory viruses. J Clin Microbiol 2013;51:1528-33.

[103] Lardinois F. Google unveils smart contact lens that lets diabetics measure their glucose levels [internet]. TechCrunch Jan 162014 [cited 2014 Aug 1]. Available from: http://techcrunch.com/2014/01/16/google-shows-off-smart-contact-lens-thatlets-diabetics-measure-their-glucose-levels/.

[104] Hubanova R, Aptel F, Chiquet C, Mottet B, Romanet JP. Effect of overnight wear of Triggerfish sensor on corneal thickness measured by Visante anterior segment optical coherence tomography. Acta Ophthalmol 2014;92:e119-23.

[105] Yilmaz T, Fostyer R, Hao Y. Detecting vital signs with wearable wireless sensors. Sensors 2010;10:10837-62.

[106] Heo YJ, Takeuchi S. Towards smart tattoos: implantable biosensors for continuous glucose monitoring. Adv Health Mater 2013;2:43-56

[107] Gandrud LM, Paguntalan HU, Van Wyhe MM, et al. Use of the Cygnus GlucoWatch biographer at a diabetes camp. Pediatrics 2004;113:108-11.

[108] Lee SM. Samsung smart watch will monitor vital signs [internet]. SFGate; May 28 2014 [cited 2014 Aug 1]. Available from: http://www.sfgate.com/technology/article/Samsung-smart-watch-will-monitor-vital-signs-5511554.php.

[109] Scanadu ScoutTM [Internet]. [cited 2014 Aug 1]. Available from: https://www. scanadu.com/scout/.

[110] Hudson T. GlucoPhone: a cellphone for diabetics [internet]. [cited 2014 Aug 1]. Available from: http://gizmodo.com/194711/glucophone-a-cellphone-for-diabetics.

[111] BayerContour [Internet]. [cited 2014 Aug 1]. Available from: http://www. bayercontour.com/Blood-Glucose-Monitoring/NEXTProducts/CONTOUR-NextUSB-Meter.

[112] Tran J, Tran R, J.R. Jr White. Smartphone-based glucose monitors and applications in the management of diabetes: an overview of 10 salient "apps" and a novel Smartphone-connected blood glucose monitor clinical diabetes. Clin Diabetes 2012;30:173-8

[113] Steinhubl SR, Muse ED, Topol EJ. Can mobile health technologies transform health care? JAMA 2013;310:2395-6.

[114] Marlowe EM, Novak-Weekley SM, Cumpio J, et al. Evaluation of the Cepheid Xpert MTB/RIF assay for direct detection of Mycobacterium tuberculosis complex in respiratory specimens. J Clin Microbiol 2011;49:1621-3.

[115] Wei Q, Qi H, Luo W, et al. Fluorescent imaging of single nanoparticles and viruses on a Smart Phone. ACS Nano 2013;7:9147-55.

[116] Hartman DJ, Parwani AV, Cable B, et al. Pocket pathologist: a mobile application for rapid diagnostic surgical pathology consultation. J Pathol Inform 2014;5:10.

[117] Kaplan KJ. Needs and workflow assessment prior to implementation of a digital pathology infrastructure for the US Air Force Medical Service. J Pathol Inform 2013;4:37.
[118] Weinstein RS, Graham AR, Richter LC, et al. Overview of telepathology, virtual microscopy, and whole slide imaging: prospects for the future. Hum Pathol 2009;40: 1057-69.

[119] Stone RA, Rao RH, Sevick MA, et al. Active care management supported by home telemonitoring in veterans With type 2 diabetes. The DiaTel randomized controlled trial. Diabetes Care 2010;33:478-84.

[120] Telehealth solutions [Internet]. [cited 2014 Aug 1]. Available from: http://www. telehealth.philips.com/solution telestation.html.

[121] Park SH, Park CJ, Choi MO, et al. Automated digital cell morphology identification system (CellaVision DM96) is very useful for leukocyte differentials in specimens with qualitative or quantitative abnormalities. Int J Lab Hematol 2013;35:517-27.

[122] Titus K. Regulators scanning the digital scanners [internet]. CAP Today 2012; 12(1) [[cited 2014 Aug 1]. Available from: http://www.cap.org/apps/portlets/ contentViewer/show.do?printFriendly $=$ true\&contentReference $=$ cap_today $\%$ 2F0112\%2F0112a_regulators.html].

[123] Kampfrath T. Food and Drug Administration starts treating mobile medical apps as medical devices. Clin Chem 2014;60:428.

[124] Allen TC. Digital pathology and federalism. Arch Pathol Lab Med 2014;138:162-5

[125] Federation of State Medical Boards. Interstate medical licensure compact; May 5 2014 [[Internet]. [cited 2014 Aug 1]. Available from: http://www.fsmb.org/ Media/Default/PDF/Advocacy/Interstate\%20Compact\%20DRAFT\%20(May\%205\% 202014).pdf].

[126] Lei KF. Microfluidic systems for diagnostic applications: a review. J Lab Automat 2012;17:330-47.

[127] Affymetrix. Foundation publications [internet]. [cited 2014 Aug 1]. Available from: http://www.affymetrix.com/estore/publications/foundation.affx.

[128] Illumina. BeadArray Microarray Technology [internet]. [cited 2014 Aug 1] Available from: http://www.illumina.com/technology/beadarray-technology.ilmn.

[129] Alvarez JC, Duverneuil C, Zouaoui K, et al. Evaluation of the first immunoassay for the semi-quantitative measurement of meprobamate in human whole blood or plasma using biochip array technology. Clin Chim Acta 2012;413:273-7.

[130] Walt D. Optical methods for single molecule detection and analysis. Anal Chem 2013;85:1258-63.

[131] Freitas Jr RA. Nanotechnogy, nanomedicine and nanosurgury. Int J Surg 2005;3: 243-6.

[132] Denholm M. Cancer's new nemesis: nanorobots internet. Tech and Innovation Daily; Jan 162014 [[cited 2014 Aug 1]. Available from: http://www. techandinnovationdaily.com/2014/01/16/cancer-fighting-nanorobots/].

[133] Lefferts JA, Jannetto P, Tsongalis GJ. Evaluation of the Nanosphere Verigene System and the Verigene F5/F2/MTHFR nucleic acid tests. Exp Mol Pathol 2009;87:105-8.

[134] Patel MK, Ali MA, Zafaryab M, et al. Biocompatible nanostructured magnesium oxide-chitosan platform for genosensing application. Biosens Bioelectron 2013; 45:181-8

[135] HSE (Health, Safety Executive). Understanding the hazards of nanomaterials [internet]. 2013 [[cited 2014 Aug 1]. Available from: http://www.hse.gov.uk/nanotechnology/understanding-hazards-nanomaterials.htm].

[136] Pertea M, Salzberg L. Between a chicken and a grape: estimating the number of human genes. Gen Biol 2010;11:206-12.

[137] Hall SS. Journey to the genetic interior. Sci Am 2012;307:80-4.

[138] Venter JC, Adams MD, Myers EW, et al. The sequence of the human genome. Science 2001;391:1304-51.

[139] Mardis ER. Next-generation sequencing platforms. Annu Rev Anal Chem 2013: 287-303.

[140] de Leon J, Susce MT, Murray-Carmichael E. The AmpliChipTM CTP450 genotyping test. Mol Diagn Ther 2006:10:135-51.

[141] FDA News Release. FDA allows marketing for first of-its-kind post-natal test to help diagnose developmental delays and intellectual disabilities in, children [internet]; Jan 172014 [cited 2014 Aug 1].

[142] Ried T, Evelin Schrock E, Yi Ning Y, Johannes Wienberg J. Chromosome painting: a useful art. Hum Mol Genet 1998;7:1619-26.

[143] Pearce DM, Styles DN, Hardick JP, Gaydos CA. A new rapid molecular point-of-care assay for Trichomonas vaginalis: preliminary performance data. Sex Transm Infect 2013;89:495-7.

[144] Prainsack B, Wolinsky H. Direct-to-consumer genome testing: opportunities for pharmacogenomics research? Pharmacogenomics 2010;11:651-5.

[145] Kruse D. Complete Genomics adds 29 high-coverage, complete human genome sequencing datasets to its public genomic repository [internet]. [cited 2014 Aug 1]. Available from: http://www.completegenomics.com/ newsevents/pressreleases/archive/Complete-Genomics-Adds-29-High-Coverage-Complete-Human-Genome-Sequencing-Datasets-to-its-Public-Genomic-Repository-119298369.html.

[146] Gryta T. What is a "pharmacy benefit manager"? [Internet]. Wall St J July 212011 [[cited 2014 Aug 1]. Available from: http://online.wsj.com/news/articles/ SB10001424053111903554904576460322664055328].

[147] Carlson JJ, Roth JA. The impact of the Oncotype Dx breast cancer assay in clinical practice: a systematic review and meta-analysis. Breast Cancer Res Treat 2013; 141:13-22.

[148] Slodkowska EA, Ross JS. MammaPrint 70-gene signature: another milestone in personalized medical care for breast cancer patients. Expert Rev Mol Diagn 2009;9: 417-22.

[149] FDA. Draft guidance for industry, clinical laboratories, and FDA staff - in Vitro Diagnostic Multivariate Index Assays [internet]. [cited 2014 Aug 1]. Available from: http://www.fda.gov/MedicalDevices/DeviceRegulationandGuidance/ GuidanceDocuments/ucm079148.htm.

[150] Economist. An array of errors [internet]. [cited 2014 Aug 1]. Available from: http:// www.economist.com/node/21528593; Sep 102011. 
[151] Park JY, Kricka LJ, Clark P, Londin E, Fortina P. Clinical genomics: when whole genome sequencing is like a whole body CT scan. Clin Chem 2014 Aug 11. pii: clinchem.2014.230276.

[152] Genomics England. About the 100K Genome Project [internet]. [cited 2014 Aug 1] Available from: http://www.genomicsengland.co.uk/100k-genome-project/.

[153] BGI. Million Human Genomes Project [internet]. [cited 2014 Aug 1]. Available from: http://www.genomics.cn/en/navigation/show_navigation?nid=5658.

[154] Wetterstrand KA. DNA sequencing costs: data from the NHGRI Genome Sequencing Program (GSP) [internet]. [cited 2014 Aug 1]. Available from: www.genome.gov/ sequencingcosts.

[155] Hayden EC. Is the $\$ 1,000$ genome for real? Nature Jan 15 2014. http://dx.doi.org/ 10.1038/nature.2014.14530.

[156] Howell RR, Terry S, Tait VF, et al. CDC grand rounds: newborn screening and improved outcomes. Morbidity Mortality Wkly Rep (MMWR) 2012;61:390-3.

[157] Wang J, Gotway G, Pascual JM, Park JY. Diagnostic yield of clinical next-generation sequencing panels for epilepsy. AMA Neurol 2014;7:650-1.

[158] Anderson NG, Anderson NL. The human protein index. JAMA 1981;246:2621.

[159] Martiny D, Busson L, Wybo I, El Haj RA, Dediste A, Vandenberg O. Comparison of the Microflex LT and Vitek MS systems for routine identification of bacteria by matrix-assisted laser desorption ionization-time of flight mass spectrometry. J Clin Microbiol 2012;50:1313-25.

[160] Kruppa G, Sparbier K, Lange C, Kostrzewa M, Jung J, Schubert S. Automated evaluation of the MALDI-TOF MS-based functional $\beta$-lactamase assay. Poster: ASMS 2013:A101.

[161] National Cancer Institute. What is cancer proteomics? [Internet]. [cited 2014 Aug 1]. Available from: http://proteomics.cancer.gov/whatisproteomics.

[162] Hartmann M, Roeraade J, Stoll D, Templin MF, Joos TO. Protein microarrays for diagnostic assays. Anal Bioanal Chem 2009;393:1407-16.

[163] Todd J, Freese B, Lu A, et al. Ultrasensitive flow-based immunoassays by use of single-molecule counting. Clin Chem 2007;53:1990-5.

[164] Boja ES, Jortani SA, Ritchie J, et al. The journey to regulation of protein-based multiplex quantitative assays. Clin Chem 2011;57:560-7.

[165] Micheel CM, Nass CJ, Omenn GS, editors. Evolution of translational omics: lessons learned and the path forward. Institute of Medicine of the National Academies: 2012.

[166] Zhi M, Ding EL, Theisen-Toupal J, Whelan J, Arnaout R. The landscape of inappropriate laboratory testing: a 15-year meta-analysis. PLoS One 2013:e78962.

[167] Price CP, Christenson RH. Ask the right question: a critical step for practicing evidence-based laboratory medicine. Ann Clin Biochem 2013;50:306-14.

[168] Smith R, Rennie D. Evidence-based medicine - an oral history. JAMA 2014;311: 365-7.

[169] National Institute for Health and Care Excellence. Guidance [internet]. [cited 2014 Aug 1]. Available from: https//www.guidance.nice.org.uk/guidance.

[170] CDC. Laboratory medicine quality improvement [internet]. [cited 2014 Aug 1] Available from: http://www.cdc.gov/osels/lspppo/Laboratory_Medicine_Quality Improvement/\#evidence; 2013.

[171] Squires D. Explaining high health care spending in the United States: an international comparison of supply, utilization, prices, and quality. The Commonwealth Fund 2012;10:1-14

[172] Ladanyi M, Chan WC, Triche TJ WL. Expression profiling of human tumors: the end of surgical pathology? J Mol Diagn 2001;3:92-7.

[173] Pantanowitz L, Wiley CA, Demetris A, et al. Experience with multimodality telepathology at the University of Pittsburgh Medical Center. J Pathol Inform 2012;3:45.

[174] Robboy SJ, Weintraub S, Horvath AE, et al. Arch Pathol Lab med 2013;137:1723-32

[175] Hoyert DL, Kung HC, Xu. Autopsy patterns in 2003. National Center for Health Statistics. Vital Health Stat 2007;20(32)

[176] Evans AJ, Chetty R, Clarke BA, et al. Primary frozen section diagnosis by robotic microscopy and virtual slide telepathology: the University Health Network experience. Hum Pathol 2009;40:1070-81.

[177] Stoler MH. Bethesda system: integrating cytology and HPV molecular testing [internet]. Webinar: College of American Pathologists; 2010 [[cited 2014 Aug 1] Available from: www.cap.org/apps/docs/meeting_calendar/true.pdf].
[178] Roche. FDA approves Roche's HPV test for first-line primary screening for cervical cancer [internet]. [cited 2014 Aug 1] Available from: http://www.roche.com/ media/media_releases/med-cor-2014-04-25.htm; Apr 252014.

[179] Goetz M, Malek NP, Kiesslich R. Microscopic imaging in endoscopy: endomicroscopy and endocytoscopy. Nat Rev Gastroenterol Hepatol 2014;11:11-8.

[180] Ladd ME. High-field-strength magnetic resonance: potential and limits. Top Magn Reson Imaging 2007;18:139-52.

[181] Guder WG, Buttner J. Clinical chemistry in laboratory medicine in Europe-past, present and future challenges. Eur J Clin Chem Clin Biochem 1997;35:487-94.

[182] Langlois MR, Wallemacq P. The future of hospital laboratories. Position statement from the Royal Belgian Society of Clinical Chemistry (RBSCC). Clin Chem Lab Med 2009;47:1195-201.

[183] Beastall GH. The modernization of pathology and laboratory medicine in the UK: networking into the future. Clin Biochem Rev 2008;29:3-9.

[184] Watkins Jr JE. What may happen in the next hundred years. Ladies Home J 1900;18:8

[185] Gonzalez RT. Medical predictions for the 21st century from 1955 were equal parts inspiring and gut-busting. [cited 2014 Aug 1] Available from: http://io9.com/ 5908897/medical-predictions-for-the-21st-century-from-1955-were-equal-partsinspiring-and-gut+busting; 2012.

[186] Pogoreic D. Personalized medicine by 2020 and other futuristic healthcare predictions (infographic) [internet]. MEDCITY News 2012. [cited 2014 Aug 1] Available from: http://medcitynews.com/2012/08/personalized-medicine-by-2020-thisand-other-predictions-on-the-future-of-healthcare-infographic/

[187] The Editors. 110 predictions for the next 110 years [internet]. Popular Mech 2012 [December 10, 2012] Available from: http://www.popularmechanics.com/technology/engineering/news/110-predictions-for-the-next-110-years.

[188] I look forward to. 11 predictions for the world in 2030 that may sound outrageous today but not in the future [internet]. [cited 2014 Aug 1] Available from: http:// www.ilookforwardto.com/2010/11/10-predictions-for-2030-that-may-sound-outrageous-today-but-will-not-in-the-future1-by-2030-learning-a-language-will-nolo.html; 2012.

[189] LaMontagne C. NerdWallet's top 5 predictions for the future of healthcare in 2014 [internet]. NerdWallet Health; 2013 [[cited 2014 Aug 1] Available from: http:// www.nerdwallet.com/blog/health/2013/12/09/nerdwallet-predictions-futurehealthcare-2014/]

[190] Dillow C. This is what the world will look like in 2045 [internet]. Fortune Magazine 2013. [cited 2014 Aug 1] Available from: http://money.cnn.com/gallery/technology/2013/06/20/world-in-2045.fortune/index.html

[191] Dillon K, Prokesh S. Megatrends in global health care [internet]. Harv Bus Rev Apr 2010 [[cited 2014 Aug 1] Available from: http://hbr.org/web/extras/insight-center/ health-care/globaltrends/1-slide].

[192] Morse G. Ten innovations that will transform medicine [internet]. Harv Bus Rev 2010 [[cited 2014 Aug 1] Available from: http://hbr.org/web/extras/insight-center/health-care/10innovations/1-checklists].

[193] United States Census Bureau. U.S. Census Bureau projections show a slower growing, older, more diverse nation a half century from now. 2012 [[Internet]. [cited 2014 Aug 1] Available from: https://www.census.gov/newsroom/releases/ archives/population/cb12-243.htmll.

[194] Torres C. 2012. Report: Health spending will climb to nearly one-fifth of GDP [Internet]. Kaiser Health News. [cited 2014 Aug 1] Available from: http://capsules. kaiserhealthnews.org/index.php/2012/06/report-health-spending-will-climb-tonearly-one-fifth-of-gdp/

[195] Fisher ES, Staiger DO, Bynum JPW, Gotlieb DJ. Creating Accountable Care Organizations: the extended hospital medical staff. Health Aff 2007;26:w44-57 [Millwood]

[196] Hood L, Flores M. A personal view on systems medicine and the emergence of proactive P4 medicine: predictive, preventive, personalized and participatory. New Biotechnol 2012;29:613-24.

[197] P4 Medicine Institute [internet]. [cited 2014 Aug 1] Available from: http://p4mi. org/p4medicine. 